\title{
Scope and relevance of a pulmonary biopharmaceutical classification system AAPS/FDA/USP Workshop March 16-17th, 2015 in Baltimore, MD
}

\author{
Jayne E. Hastedt ${ }^{*}$, Per Bäckman², Andrew R. Clark ${ }^{3}$, William Doub ${ }^{4}$, Anthony Hickey ${ }^{5}$, Guenther Hochhaus ${ }^{6}$, \\ Phil J. Kuehl', Claus-Michael Lehr ${ }^{8}$, Peter Mauser ${ }^{9}$, Jason McConville ${ }^{10}$, Ralph Niven ${ }^{11}$, Masahiro Sakagimi ${ }^{12}$ \\ and Jeffry G. Weers ${ }^{11}$
}

\begin{abstract}
The Biopharmaceutics Classification System (BCS), developed in the 1990s for oral immediate release drugs, is utilized by R\&D scientists and regulators to streamline product development and regulatory approval timelines. This elegant, science-based approach is based on three in vitro parameters representing a combination of drug substance physicochemical and physiological properties with respect to oral administration; specifically a dose number, dissolution number, and absorption number. Interest in applying similar principles to pulmonary drug products is increasing. To date the focus has been on dissolution of drugs in the lung. A workshop co-sponsored by the AAPS, FDA, and USP was held in March 2015 in Baltimore to evaluate if a systematic framework to classify pulmonary drugs could be established, and the scope and relevance of such a classification scheme. The focus of the workshop was to address factors influencing drug delivery and action in the lungs rather than the development of a specific model or system. Presentations included: the history and evolution of the oral BCS (described as the "giBCS" by Gordon Amidon), lung physiology and the fate of inhaled drugs, regional aerosol deposition and dose, macroscopic clearance mechanisms, particle dissolution, drug permeability, absorption and their interplay with pharmacokinetics and pharmacodynamics. Background discussions were followed by three separate breakout sessions each focused on the BCS concepts of dose, dissolution, and absorption numbers as they would apply to pulmonary drug delivery. The workshop concluded that a classification system, if fully developed, would be a useful tool for formulators and discovery chemists. The scope of such a system, at this point in time, would not include aspects relevant to regulatory relief. The goals of the workshop were met by identifying an opportunity to develop a model to classify pulmonary drugs based on physicochemical attributes specific to lung physiology and drug delivery.
\end{abstract}

Keywords: BCS, Physical pharmacy, Physicochemical characterization, Particle dissolution, Lung dose, Dose number, Absorption number, Dissolution number, Pulmonary deposition, Pulmonary absorption, Pulmonary defenses, Fate of inhaled drugs, Inhalation, Respiratory drug delivery

\footnotetext{
* Correspondence: jayne@jdppharma.com

'JDP Pharma Consulting, LLC, San Carlos, CA, USA

Full list of author information is available at the end of the article
} 


\section{Background}

The workshop was opened by Jayne Hastedt (JDP Pharma Consulting, USA) who challenged attendees to think about how differences in location and conditions in the lungs vs GI might affect efficacy and safety of drugs delivered to those locations and how better knowledge of those factors might lead to more facile development of new pulmonary pharmaceuticals. The following is a summary of that commentary which included a presentation by Gordon Amidon (University of Michigan, USA) on the development of the giBCS some 20 years ago.

The systemic absorption and distribution of a drug substance from a dosage form is dependent primarily upon the physicochemical properties of the drug, the dose administered, and the permeability and pharmacokinetics associated with the route of administration. An approach to classify orally administered drugs based on a macroscopic assessment of gastrointestinal permeability and aqueous solubility was first introduced in the 1990s (Amidon et al. 1995). Even though this Biopharmaceutical Classification System (giBCS) has been revised over the ensuing years, the goal has remained the same. The giBCS model for orally administered drugs provides a basis for correlating in vitro drug product dissolution to in vivo bioavailability assuming that drug dissolution, drug dose, and GI permeability are the attributes dictating the rate and extent of drug absorption via the oral route of administration (USDHHS/FDA 2015).

In contrast, drugs delivered via inhalation are typically not intended for systemic administration. Inhaled drugs, classically designed to treat diseases of the lung, are deposited within the complex and diverse architecture of that organ. Instead of swallowing the dosage form to deliver a dose of active drug to the GI for absorption and distribution, inhaled drugs are administered using an inhalation device that delivers a nominal dose. The inhalation delivery route adds the complications that drug deposition within the lung and the dose to the lung are primarily influenced by the inhalation device design, aerodynamic particle size and distribution of the dispersed product, fluid mechanics, and the way the patient interacts with the drug delivery device. Although an inhalation drug classification system has not been established to date, at least one paper has been published on this topic (Eixarch et al. 2010). For inhaled drug products, development of a classification system that combines the physicochemical properties of the drug, the critical quality attributes of the product, and the biology of the lung is the first step in understanding the role of in vitro performance parameters as they affect in vivo product performance.
In order to assess whether or not a biopharmaceutical characterization approach can be developed for inhaled drugs, appropriate biorelevant properties of pulmonary drugs (e.g., solubility, dissolution, permeability) need to be identified. This would be followed by a thorough study of the relationship between the biopharmaceutical properties and the unique physiological attributes of the target organ, and in this case, the lung and the distinctive attributes of the pulmonary product. These parameters include: retention time in the lung, the amount and type of "fluid" available for dissolution, physiology of the various regions of the lung, lung dose, and deposition patterns.

A characterization system based on the biopharmaceutical properties of inhaled drugs was explored at the Inhalation Biopharmaceutical Product Classification System Development: Challenges and Opportunities workshop held in March 2015 in Baltimore ${ }^{1}$. The workshop was co-sponsored by the AAPS, FDA, and USP. The goal of the workshop was to investigate whether or not development of a classification system based on physiologically relevant physicochemical properties of pulmonary drugs could prove beneficial to the development of inhaled drug products. The giBCS approach was used as a starting point for the workshop discussions. The following topical areas were explored as refinements to address the differences/similarities between the GI and the lung:

- Lung permeability and transport

- The role of fluid mechanics in pulmonary drug deposition

- Particle dissolution in the lung and in vitro testing as applicable to lung particle dissolution

- PK/PD modeling for lung delivery.

Fifty-four senior level pharmaceutical scientists, engineers and physicists, clinical pharmacokineticists, toxicologists, regulators, and academicians working in the inhalation field attended the workshop. Attendees were drawn from 15 US states plus 7 foreign countries and included 9 representatives from government agencies, 10 from academia, and 35 from industry, including contract pharma representatives. After 2 days of deliberation attendees agreed that a classification system for inhaled drug products would be beneficial to formulators and drug discovery chemists. Therefore efforts to identify attributes similar to the giBCS approach (e.g., dose number, dissolution number, and absorption number) for inhaled drug products will be one of the next steps in this effort. All attendees agreed that any attempt to relate these attributes to bioequivalence of inhaled drug products was beyond the scope of the current effort. 
This article contains a summary of the scientific presentations and the overall conclusions and next steps identified during the workshop.

\section{Discussion}

\section{Lung physiology and the fate of inhaled drugs}

Before proceeding to the factors influencing the delivery, dissolution and disposition of aerosol particles delivered to the lungs, the environment in which they will deposit must be described sufficiently for the later consideration. The topics considered in the following section describe the structure and function of the lungs and regions within it from a macroscopic, organ system, anatomical, and microscopic, composite-cell scale to help frame later discussion of the interactions of drugs with the various interfaces that govern bioavailability and efficacy. This section reflects presentation materials provided by Pete Mauser (Merck R\&D, USA), Claus-Michael Lehr, (Saarland University, Germany), and Ralph Niven (Novartis, USA) during the workshop.

\section{Basic physiology of the respiratory tract}

The lungs (Fig. 1) are a complex organ system designed to enable the efficient exchange of gases between the blood and the respiratory airspace. The fact that the lungs have developed sophisticated, multi-tiered defenses directed to removing particulate and soluble material that would not normally be resident in the airspaces presents an ongoing challenge for inhalation therapies (Albertine 2010; Olsson et al. 2011).

Functionally, the lungs can be thought of as having two distinct zones. The first is composed of a tubular

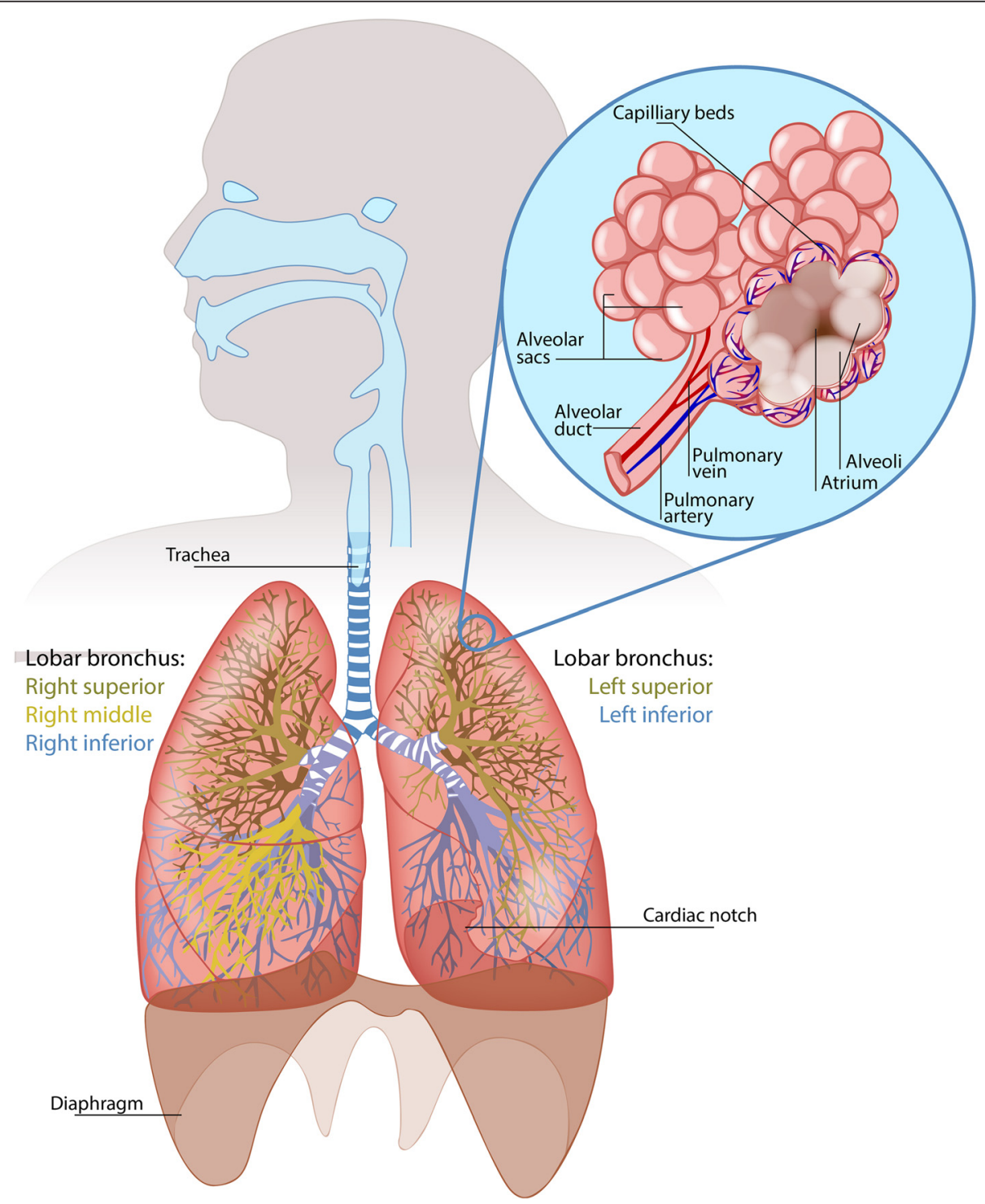

Fig. 1 Pulmonary drug delivery 
conduit system for the transport of gases to and from the external environment and the second is a respiratory zone where gas exchange takes place. The tracheobronchial tree bifurcates repeatedly creating up to 23 divisions before reaching the alveoli (16 divisions in the 'transport' or 'conducting' zone and another 7 within the respiratory zone) (Table 1) (Hickey \& Thompson 1992; Moffet et al. 1993; Weibel 1963).

With each division of the tracheobronchial tree there is a reduction in diameter of the bronchi, a shortening of their length, an increase in their number and a concomitant increase in the surface area (Hickey \& Thompson 1992; Moffet et al. 1993; Weibel 1963).

\section{Pulmonary defense mechanisms}

The conducting zone possesses a number of mechanisms that protect the lungs:

1. Anatomically, the repeated branching presents a defensive 'sifting' zone to 'trap' particles via inertial impaction and sedimentation while allowing inhaled gases to be humidified and warmed to body temperature.

2. A gel/sol lining fluid with ciliated epithelium captures particles deposited on the airways and transports them via the mucociliary escalator to the oropharynx whereupon they are swallowed.

3. Beneath this lining fluid is a highly responsive airway epithelium intimately associated with a variety of cells of the innate and adaptive immune system
4. A variety of neuronally-linked receptors (e.g. lung irritant receptors (LIR) and C fibers) that can induce mechanical clearance mechanisms, such as cough, changes in breathing pattern and bronchial tone in response to particles and dissolved mediators.

The respiratory zone is made up of functional units (some 15,000 or so in the lungs (Hansen \& Ampaya 1974)). Each unit consists of a terminal bronchiole, a respiratory bronchiole, alveolar ducts and alveolar sacs: collectively referred to as the acinus. Because airflow velocity decreases from $150 \mathrm{~cm} / \mathrm{s}$ in the upper conducting airways to nearly zero in the peripheral airways, movement of both particles and gases is via mass-action or diffusion within the acinus and is primarily concentrationdriven. Particles that deposit and persist in this environment will be dispersed or cleared by surfactant and phagocytic cells.

\section{Cellular barriers and mechanisms of clearance}

As shown in Fig. 2, the cellular morphology of the pulmonary mucosa along the respiratory tract changes significantly, in parallel with its physiological function. In the conducting airways, the cells are columnarshaped and ciliated. This cell morphology transitions to a cuboidal form deeper in the respiratory tree and eventually takes on a squamous configuration in the alveoli. Two prominent cell types (epithelial type I (ET-1) and II (ET-II) cells) can be distinguished in the alveoli. Although the ET-II cells dominate in

Table 1 A schematic representation of airway branching in the human lung

\begin{tabular}{|c|c|c|c|c|c|c|c|c|}
\hline & \multicolumn{2}{|c|}{ generation } & $\begin{array}{c}d \\
(\mathrm{~cm})\end{array}$ & $\begin{array}{c}\text { I } \\
(\mathrm{cm})\end{array}$ & number & $\begin{array}{c}\text { cross- } \\
\text { section } \\
\text { area } \\
(\mathrm{cm} 2) \\
\end{array}$ & cartilage & $\begin{array}{l}\text { epithelial } \\
\text { cell type }\end{array}$ \\
\hline \multirow{8}{*}{ 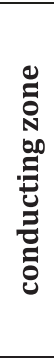 } & trachea & 0 & 1.8 & 12.0 & 1 & 2.54 & \multirow{2}{*}{$\begin{array}{l}\text { open } \\
\text { rings }\end{array}$} & \multirow{7}{*}{$\begin{array}{l}\text { columnar } \\
\text { ciliated }\end{array}$} \\
\hline & \multirow{3}{*}{ bronchi } & 1 & 1.22 & 4.8 & 2 & 2.33 & & \\
\hline & & 2 & 0.83 & 1.9 & 4 & 2.13 & \multirow{5}{*}{ plates } & \\
\hline & & 3 & 0.56 & 0.8 & 8 & 2.00 & & \\
\hline & bronchioles & 4 & 0.45 & 1.3 & 16 & 2.48 & & \\
\hline & \multirow{3}{*}{$\begin{array}{c}\text { terminal } \\
\text { bronchioles }\end{array}$} & 5 & 0.35 & 1.07 & 32 & 3.11 & & \\
\hline & & $\downarrow$ & $\downarrow$ & $\downarrow$ & $\downarrow$ & $\downarrow$ & & \\
\hline & & 16 & 0.06 & 0.17 & $6 \times 10^{4}$ & 180.0 & & cuboidal \\
\hline \multirow{7}{*}{ 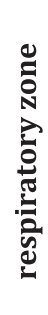 } & \multirow{3}{*}{$\begin{array}{l}\text { respiratory } \\
\text { bronchioles }\end{array}$} & 17 & & & & & & \multirow{3}{*}{$\begin{array}{c}\text { cuboidal } \\
\text { to } \\
\text { alveolar }\end{array}$} \\
\hline & & 18 & $\downarrow$ & $\downarrow$ & $\downarrow$ & $\downarrow$ & & \\
\hline & & 19 & 0.05 & 0.10 & $5 \times 10^{5}$ & $10^{3}$ & absent & \\
\hline & \multirow{3}{*}{$\begin{array}{l}\text { alveolar } \\
\text { ducts }\end{array}$} & 20 & & & & & & \multirow{4}{*}{ alveolar } \\
\hline & & 21 & & & & & & \\
\hline & & 22 & $\downarrow$ & $\downarrow$ & $\downarrow$ & $\downarrow$ & & \\
\hline & alveolar sacs & 23 & 0.03 & 0.03 & $8 \times 10^{6}$ & $10^{4}$ & & \\
\hline
\end{tabular}




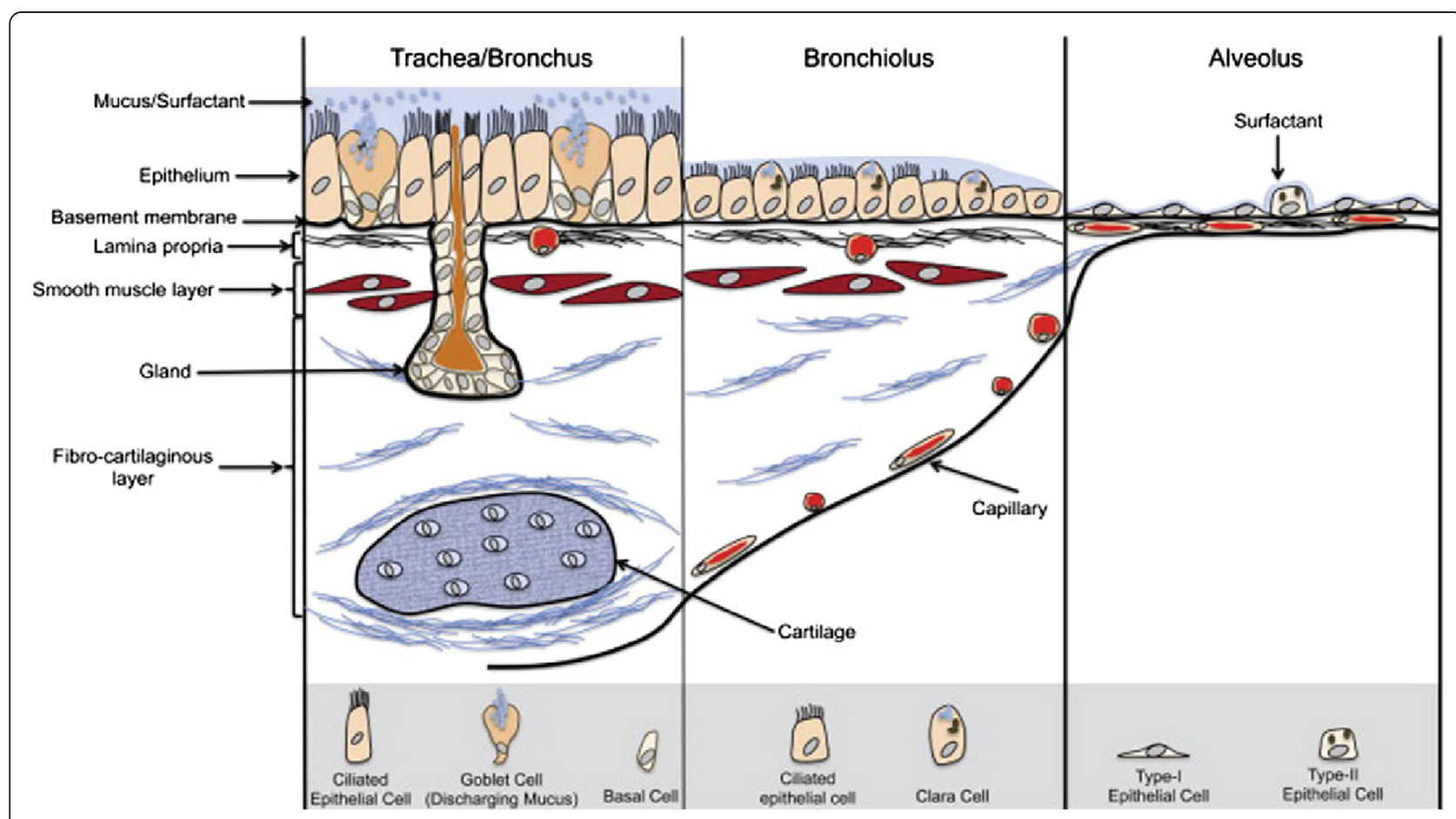

Fig. 2 Throughout the respiratory tract, the cell type and morphology changes in concert with their physiological function (Hittinger et al. 2015), adapted from (Klein et al. 2011)

terms of number (about 70-90\%), the ET-I cells cover $90+\%$ of the surface area and are therefore the major cell type forming the 'air-blood-barrier' of the lungs. The combination of a large alveolar surface area $\left(>100 \mathrm{~m}^{2}\right)$ and small diffusion distances between blood and airspaces $(\sim 1 \mathrm{um})$, facilitate effective pulmonary gaseous exchange.

Pulmonary surfactant is a complex lipoprotein mixture that, among other functions, helps maintain the patency of the airspaces during inhalation maneuvers. Within the alveoli, the overall lining layer has a harmonic mean thickness of $<0.2 \mu \mathrm{m}$ but the depth can vary significantly in alveolar pockets. The surfactant may strongly influence the dispersion of drugs depositing on the alveolar surface depending upon the physicochemical characteristics of the agent.

The primary, resident phagocytic cell is the alveolar macrophage (MØ). It is estimated that over 2.3 billion of these cells are present throughout the lungs in a healthy individual and some 1-3 of these cells may be present at various locations within each alveolus (Table 2). Particles in the alveolus activate type 1 epithelial responses, which in turn attract $M \varnothing$ activity through chemokine release and other signaling pathways. MØs and other phagocytic cells (e.g., neutrophils and T-cells) can rapidly be recruited to the airspaces in response to signals from the pneumocytes or other sources.

Table 2 Characteristic Cell Numbers and Lung Values

\begin{tabular}{llll}
\hline Parameter & Value & Unit & Reference \\
\hline Alveolar Surface Area & 143 & $\mathrm{~m}^{2}$ & (Gehr et al. 1978) \\
\# of alveoli (adult lung) & $250+$ & Million & (Crapo et al. 1982) \\
\# of type I pneumocytes & 1.9 & Billion & (Crapo et al. 1982) \\
\# of type II pneumocytes & 3.7 & Billion & (Crapo et al. 1982) \\
\# of resident macrophages & 2.3 & Billion & um \\
Depth of airway fluid & $5-10$ & um et al. 1982) \\
Harmonic mean depth of alveolar fluid & 0.2 & um & (Widdicombe 2002) \\
Diameter of an alveolus & $200-250$ & & (Bastacky et al. 1995) \\
\hline
\end{tabular}


Phagocytosis will result in clearance via a combination of slow enzymatic disposal, transport along the alveolar surface to the mucociliary escalator and/or translocation to the interstitium and tracheobronchial lymphatic capillaries.

\section{Mucus and surfactant as a non-cellular barrier}

The pulmonary barrier is also comprised of important extracellular elements. Any particulate matter deposited in the conducting airways will be removed relatively quickly with a half-life of approximately 1 to $1.5 \mathrm{~h}$ by the "mucocillary escalator" (Agnew et al. 1986). Mucus is a natural glycoprotein-hydrogel and has some unique structural and rheological features that enable it to trap particles while also acting as a diffusional barrier for dissolved solutes. The continuous transport of mucus toward the proximal trachea and esophagus limits any accumulation of particles within the conducting airways. Within the alveoli, pulmonary surfactant forms a monolayer on the alveolar lining fluid. It consists predominantly of phospholipids, but also some specific surfactant proteins, referred to as SP-A,-B,-C, and -D. Surfactant proteins $B$ and $C$ are primarily associated with the surface tension lowering properties of the surfactant while A and D are involved in host-defense. Surfactant also contributes to clearance of particles from the lungs via dispersion and adsorption. The interaction of nanoparticles with the alveolar lining fluid leads to the formation of a peculiar "corona" around the nanoparticles, which in turns mediates their interaction with cells. The two scenarios that particles may encounter after deposition in either the bronchial or alveolar part of the lungs, respectively, are summarized in Fig. 3. The composition, approximate layer thickness, and approximate total layer volumes for upper airway mucus and alveolar surfactant are summarized in Table 3.

\section{Drug transport and metabolism}

Drugs or solutes that 'survive' and reach the epithelial surface can be removed from the airspaces by translocation across the epithelium. This may occur via a number of recognized, but poorly understood, mechanisms, some of which are shown in Fig. 4. It should be noted that these mechanisms also exist in the alveolus.

Drugs may be metabolized when transported via airway epithelial cells, Clara cells or via metabolicallyactive type II pneumocytes. Bio-active agents may also be degraded by a host of membrane-bound, secreted or shed enzymes released from a variety of sources.

Our knowledge about specific transporter systems, as well as efflux pumps and metabolizing enzymes in the lungs is currently still in its infancy, although there is evidence of transporters in context of pulmonary drug absorption and delivery (Patton et al. 2010). Another important consideration for inhalation drug delivery is fluid transport. Fluid levels are tightly-controlled in the lungs but through manipulation of channels such as $\mathrm{eNaC}$ and Aquaporin, micro-focal changes in fluid depth can readily be enacted and thus influence the solubility and dispersion of particles on the apical surface.

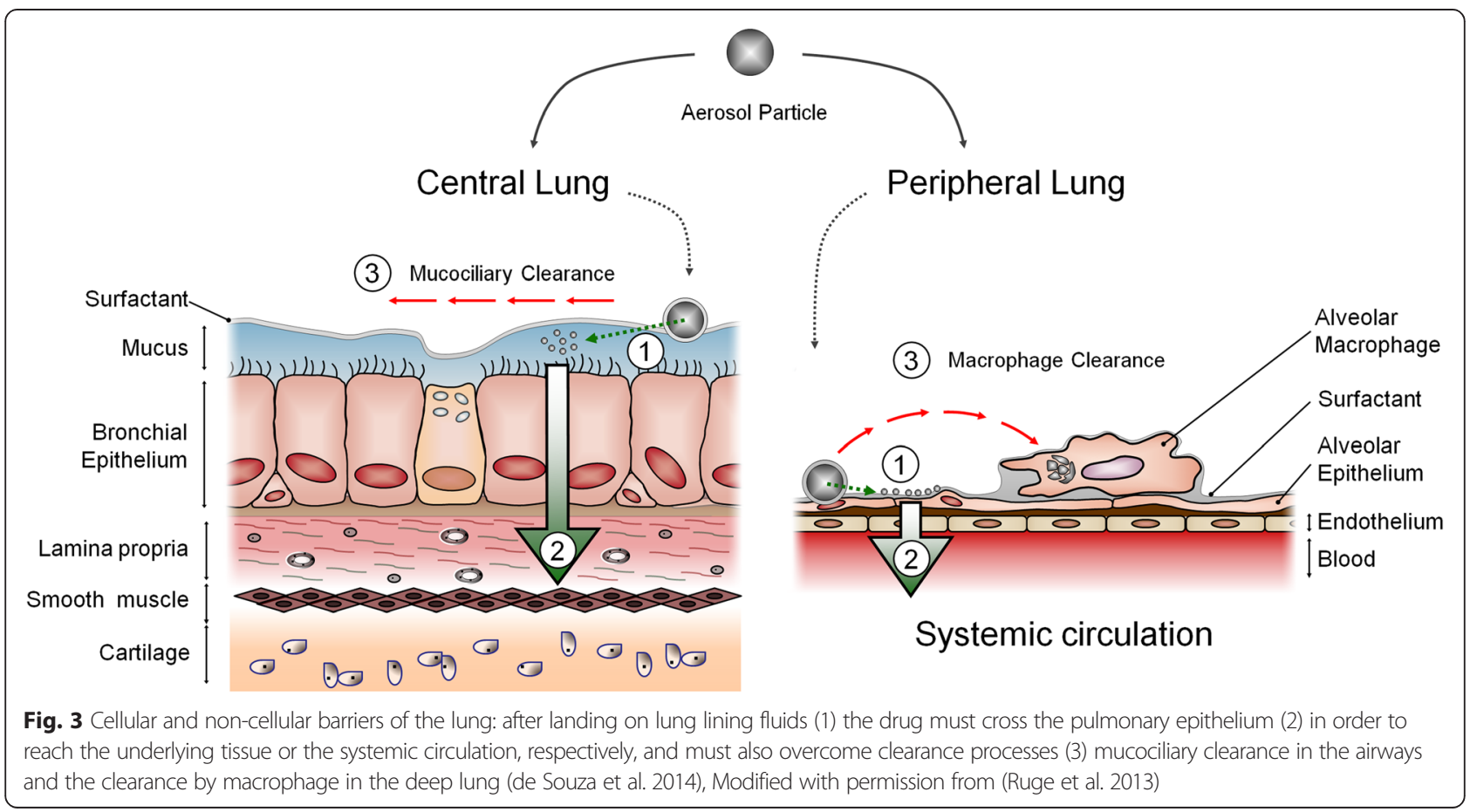


Table 3 Composition of lung lining fluid in conducting airways and respiratory zone (from (Eixarch et al. 2010) and (Hastedt 2014))

\begin{tabular}{lll}
\hline & Conducting airways & Respiratory Zone \\
\hline Principal lining fluid & Mucus & Surfactant \\
Composition of fluid layer & $1 \%$ inorganic salts & $85 \%$ phospholipids \\
& $1 \%$ proteins & $5 \%$ cholesterol \\
& $2 \%$ glycoproteins (mucins) & $10 \%$ surfactant proteins (e.g., SP-A, SP-B, SP-C, SP-D) \\
& $1 \%$ lipids & \\
& $95 \%$ water & $\sim 0.07 \mu \mathrm{m}$ \\
Layer thickness & $3-15 \mu \mathrm{m}$ (decreases in thickness in lower airways) & $7-20 \mathrm{ml}$ \\
\hline
\end{tabular}

\section{The lungs vs. the gastro-intestinal tract}

We see that there are some important differences to be considered if a characterization system such as the giBCS is to be applied to inhaled drugs. Fundamentally, the role of the gut is to accept foreign material for processing, uptake and expulsion. In contrast, the lungs are designed to remove foreign material in order to maintain gas exchange. They act more like a selective "sieve" or a "leaky bucket" than a "tube", which necessitated evolution of a variety of effective clearance mechanisms since the lung cannot rely on 'flow-through' or transit processes, as in the case of the digestive tract. While at a cellular level the general mechanisms of uptake and absorption are probably quite similar to those understood for the gut, at the macro level the lungs are quite different having a larger surface area and generally much shorter exchange-distances. Further, a highly variable milieu exists in the gut as a function of location and food intake. So, in general, diffusion into the blood/lymph are governed by the concentration gradient, particle/ molecule size, its charge, lipophilicity and of course the membrane properties of the absorptive surface. In the next section we take a closer look at the practical aspects of drug deposition into and clearance from the lungs.

\section{Deposition and clearance}

Andy Clark (Aerogen Pharma, USA), who described the fluid mechanics behind pulmonary drug deposition, began by showing that the airways can be broken down into three compartments based upon the fate of deposited materials. In the mouth and oropharynx, insoluble materials are swallowed. In the central or conducting airways insoluble materials are cleared by the mucocilliary escalator and are eventually swallowed. In the peripheral airways insoluble materials are cleared by phagocytosis and/or other cellular clearance mechanisms (Clark et al. 2006).

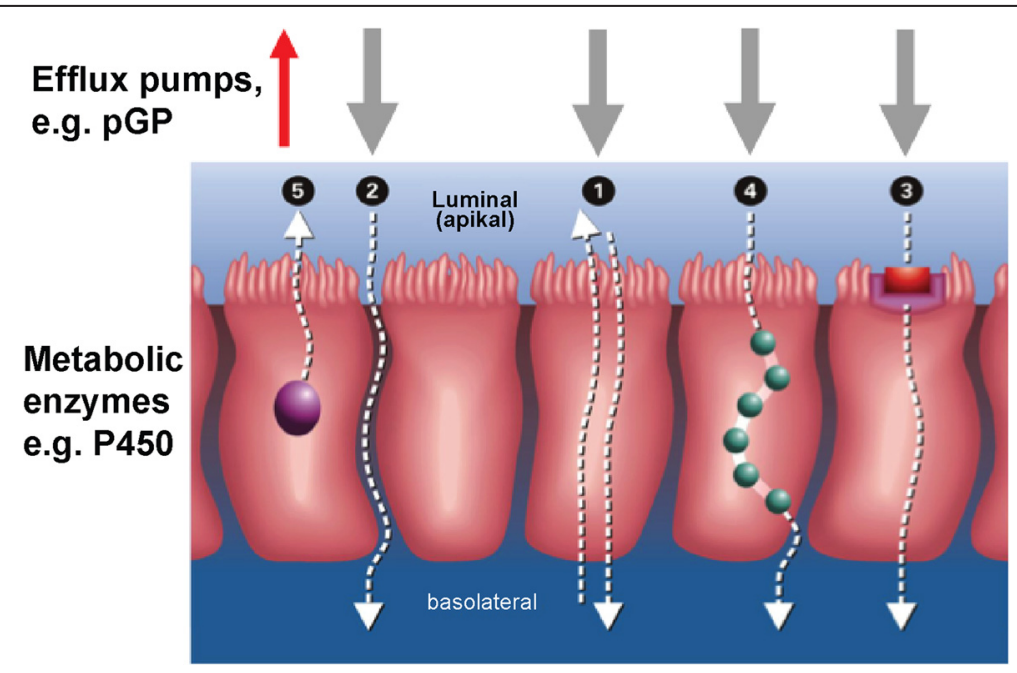

Fig. 4 Transport pathways for drugs across an epithelial barrier (Kolaca et al. 1996). (1) passive transcellular diffusion (probably for most small, sufficiently lipophilic molecules), (2.) paracellular diffusion (for hydrophilic molecules and depending on the integrity of intercellular junctions, also a pathway for peptides and proteins) (3) active transport via specific receptors and "pumps" (4) vesicular transport (endo-transcytosis) (5) efflux to the apical side and/or metabolism by epithelial cells 
In general orally inhaled drugs deposit in all three of these compartments to differing extents and, depending upon their physico-chemical properties, may be absorbed into the systemic circulation. However, the extent to which the resultant systemic exposure and pharmacokinetics contribute to efficacy depends upon the desired site of action for the molecule. For molecules intended to act systemically using the lung as a portal of entry into the circulatory system, absorption and resulting systemic levels are obviously extremely important. But for locally-acting compounds, where the intended site of action is in the lung tissue itself, systemic levels are actually only a measure of the drug that has passed through the lung tissue and is no longer available at the site of action. Similarly, where the site of action is in the airspace in the lung, such as inhaled antibiotics, systemic drug levels reflect drug that is no longer available to contribute to reducing or eliminating bacterial load. Thus, while systemic drug levels and pharmacokinetics may be useful to indicate extent of absorption and duration of absorption from the lung they are not necessarily a measure of efficacy for locally-acting drugs.

From a biopharmaceutical classification perspective, drugs reaching and depositing within the lung will experience the latter of these two environments. Soluble drugs, where dissolution and absorption are rapid compared to mucocillary clearance rates, will be absorbed from the lung almost completely with a lung bioavailability of approximately 1 . However, the absorption of insoluble or sparingly soluble drugs, or those drugs that are absorbed slowly, will be affected by the regional deposition pattern within the lung. Drug deposited in the central airways will experience a competition between clearance from the lung via the mucocillary escalator and dissolution and subsequent absorption though the lung epithelium. Whereas drug deposited in the peripheral lung essentially has "no way out" other than through absorption and cellular clearance mechanisms. Thus, the bioavailability of insoluble or slowly absorbed drugs will generally be less than one and will depend upon the regional deposition pattern. In the extreme the lung

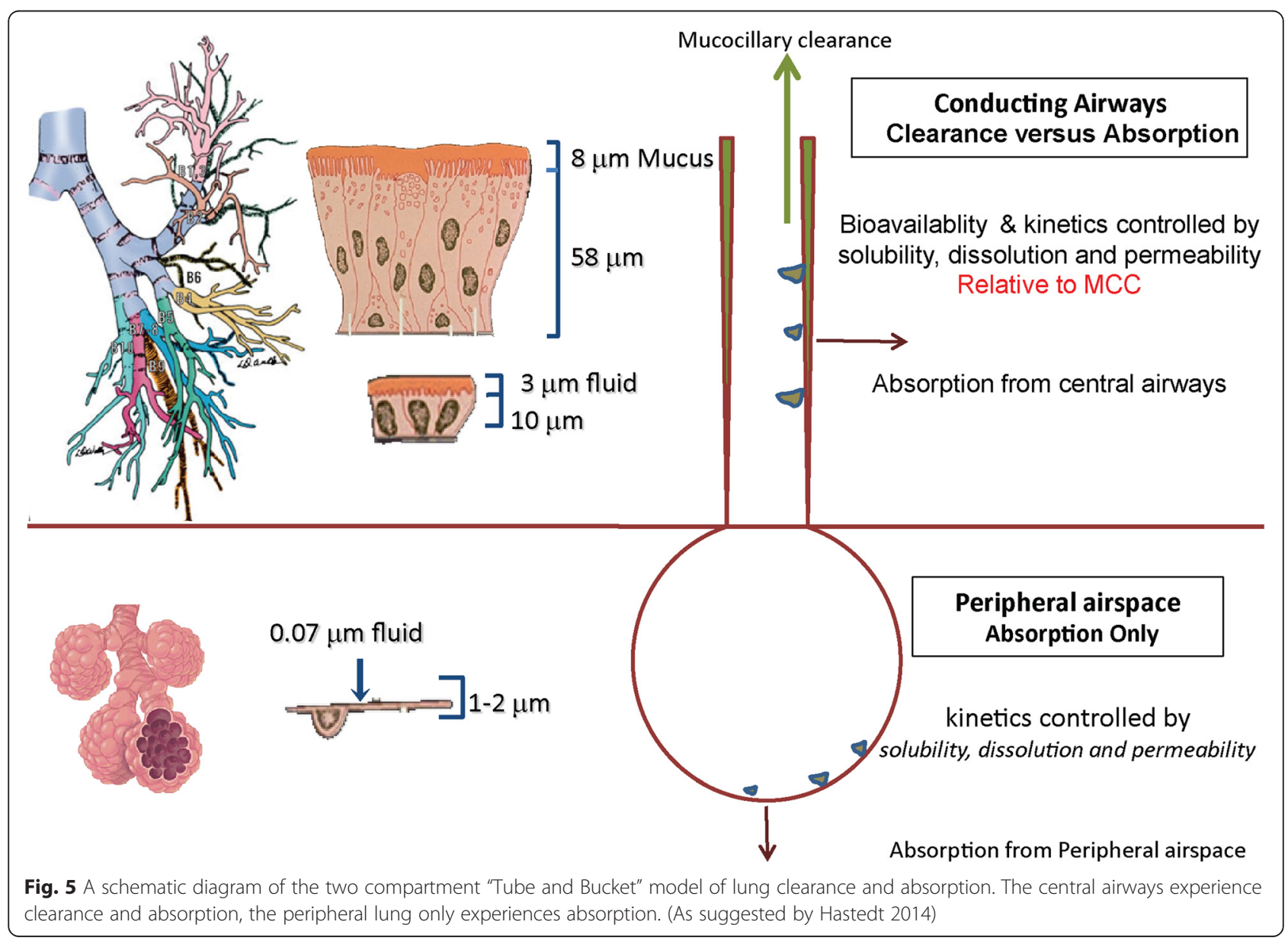


bioavailability will be equal to that fraction deposited in the peripheral airways. Figure 5 presents a simple diagram of this "tube and bucket" (Hastedt 2014) model of the lower airways illustrating the two compartments and the competing clearance and absorption mechanisms in each.

Absorption of poorly soluble, slowly absorbed molecules can obviously result in a complete lack of correlation between the total dose deposited in the lung and the resulting systemic exposure. This is illustrated in Fig. 6 for a poorly soluble selective glucocorticoid modulator, where total lung dose, predicted using a mouth/ throat model, is compared to observed AUC values in healthy volunteers (Olsson \& Bäckman 2014). The authors explain this lack of correlation as due to differences in initial regional deposition leading to variability in the fraction cleared from the central airways during absorption.

Deposition in the airways is controlled by three factors; airway geometry, aerodynamic particle size, and inhaled flow rate (Lippman 1977). Smaller particle sizes and lower flow rates result in higher lung deposition by avoiding deposition in the mouth and oropharynx and in general result in larger fractions of the lung dose depositing in the peripheral airways (Task Group on Lung Dynamics 1966; Stahlhofen et al. 1980). It should be noted here that for pharmaceutical inhalers, where a deep inspiration and breath hold are employed, less than 1 or $2 \%$ of the inhaled dose is usually exhaled (Clark 2010). Thus, with a few notable exceptions (Qvar and some formulations used in the Respimat) it is quite reasonable to

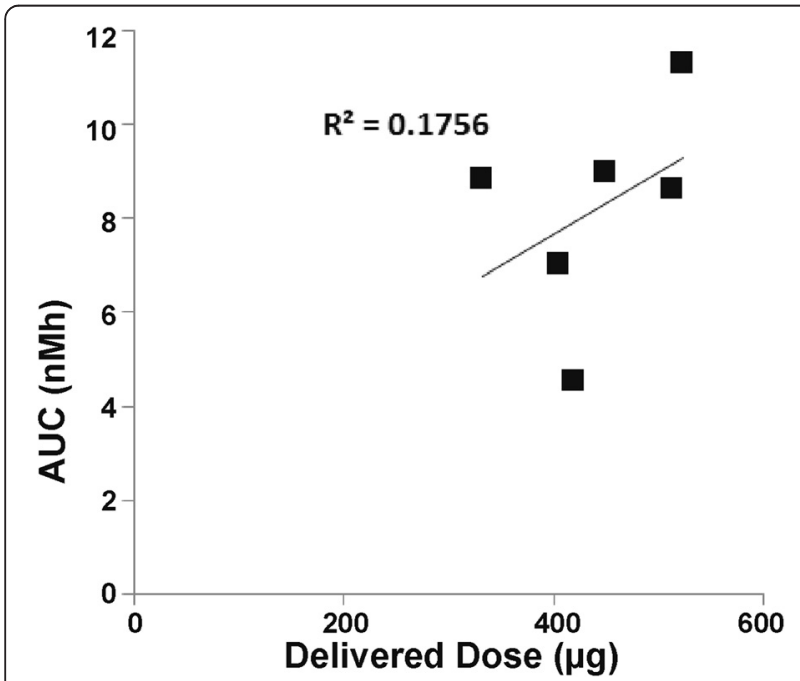

Fig. 6 A comparison of the systemic exposure (AUC) of a poorly soluble selective glucocorticoid modulator (SGRM) and the predicted total lung dose for six different devices and formulations (number of healthy volunteers ranging between 12 and 18). (From (Olsson \& Bäckman 2014)) assume that whatever gets into the lung deposits in the lung.

Figure 7 illustrates the range of drug masses deposited in the lung from various inhaler technologies and drug classes. The figure was constructed using published deposition data obtained from a variety of scintigraphy studies (Clark 2015) by taking the nominal dose for each particular product and multiplying it by the fraction deposited in the lung as determined from the gamma camera images. Two observations can be made. The first is with regard to the dosing capability of each technology, Soft Mist Inhalers can deliver up to $\sim 100 \mu \mathrm{g}$ to the lung, pressurized Metered Dose Inhalers up to $\sim 800 \mu \mathrm{g}$, Dry Powder Inhalers up to $10 \mathrm{mg}$ and finally nebulizers which in principle can deliver several hundred milligrams to lung depending on drug solubility and the acceptability of long nebulization times. The second observation, particularly relevant here, is the lung dose by drug class. Highly potent $\beta 2$ agonists and anticholinergics represent the lowest lung doses and inhaled antibiotics the highest, with the lung dose obviously being a manifestation of the potency of drug being inhaled. The overall concentration of drug in the lung, assuming instantaneous dissolution and a fluid volume of $50 \mathrm{~mL}$ (Clark et al. 2006), thus ranges from $1 \mu \mathrm{g} / \mathrm{mL}$ to 6 or $8 \mathrm{mg} / \mathrm{mL}$ depending up on the drug.

However, this is an average concentration and the actual concentrations will vary by location both due to variation in fluid volume in different generations of the airways and due to regional deposition patterns of the deposited drug. Figure 8 (Clark 2012) illustrates the regional deposition patterns obtained with various drug products using different inhaler technologies. The data were derived from scintigraphy studies using peripheral to central "regions of interest" (Newman et al. 1998) and calibrations correlating the $\mathrm{P} / \mathrm{C}$ ratios to $24 \mathrm{~h}$ clearance using insoluble radiolabeled markers (for more details see (Clark 2012)). It can be seen from the figure, by comparing the $\mathrm{P} / \mathrm{C}$ ratio for pulmonary products with the 24-h retention values from the calibration, that the fraction of the total lung dose deposited in the periphery varies from around 0.4 to 0.6 . While this might seem a rather small range it should be remembered that the inhaled aerosol entering the trachea, and thus reaching the lung, has been "prefiltered" by the mouth and oropharynx and does not have as broad or as variable size distribution as that initially generated by the inhaler device. This rather narrow range is a manifestation of the interaction between the capture efficiency of the mouth and oropharynx and that of the conducting airways.

In order to put these lung doses and regional deposition patterns into perspective it is useful to refer again to Fig. 5. Remembering that for highly soluble and rapidly absorbed molecules the lung dose and regional 


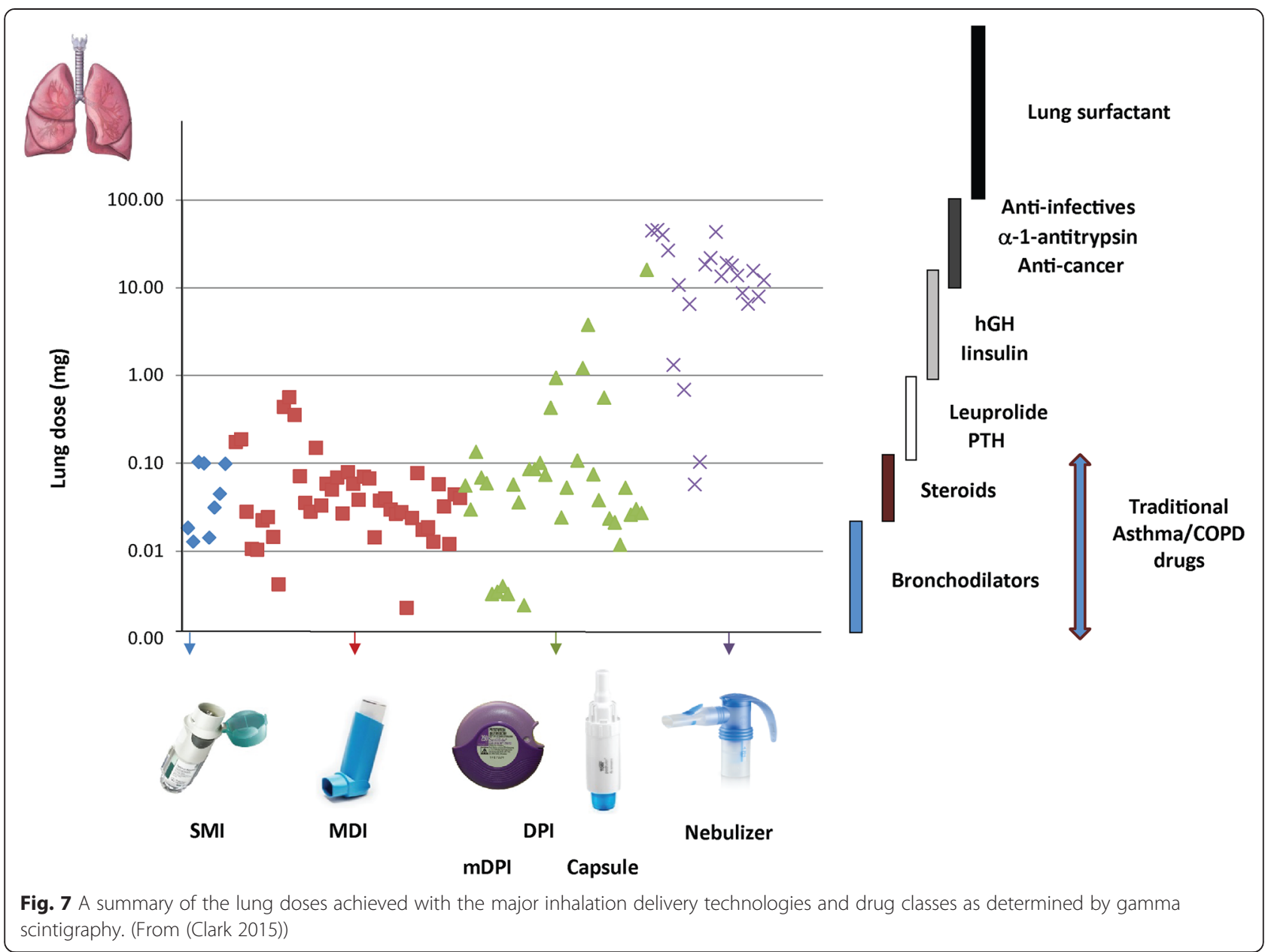

deposition pattern will not affect the systemic bioavailability, which will essentially be close to 1 when determined on the basis of total lung dose. For very insoluble drugs or poorly absorbed molecules the systemic bioavailability will be equal to that fraction of the dose deposited in the peripheral region of the lung, or on average approximately $50 \%$.

However, it is worth mentioning again that absorption and availability in the systemic circulation is not necessarily an indicator of presence or duration of action at a receptor. Rather it is a measure of drug that has passed through the lung and is no longer present to exert a local effect. In this regard the efficacy picture is much more complex than that provided by looking only at deposition, clearance and absorption and great care needs to be taken in interpreting clearance, dissolution, absorption and systemic levels in terms of the efficacy of locally acting drugs. Once deposition of drug particles has occurred, the next phenomenon to be considered is the dissolution of those particles. In the following section, we undertake a more detailed consideration this event.

\section{Particle dissolution}

Jeff Weers (Novartis, USA) provided the basic principles to be considered for particle dissolution in the lungs beginning with how Amidon et al. began their classic paper on biopharmaceutical drug classification with the following statement: "Drug dissolution is a prerequisite to drug absorption and clinical response for almost all drugs given orally" (Amidon et al. 1995). This statement is also true for drugs administered via oral inhalation (Hastedt 2014). Amidon et al. (Amidon et al. 1995) derived two dimensionless numbers (i.e., the dose number, Do and the Dissolution Number, Dn) that were used to assess drug dissolution. The Dose Number, Do, provides a measure of the impact of drug solubility on dissolution, vis:

$$
D o=\frac{M_{0} / V_{0}}{C_{s}}
$$

Where $M_{0}$ is the dose, $V_{0}$ is the volume of dissolution fluid, and $C_{s}$ is the drug solubility. For orally administered drugs, $V_{0}$ is assumed to be the initial gastric 


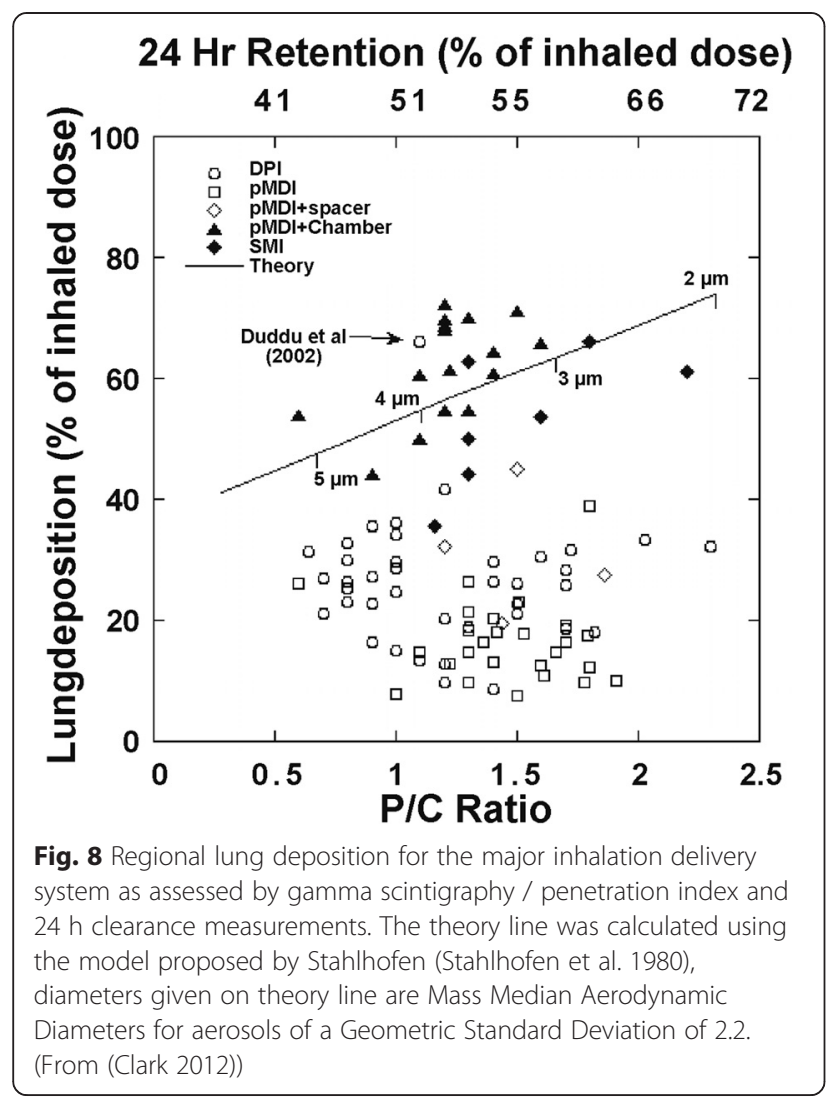

volume of $250 \mathrm{~mL}$. For inhalation drugs, $D o$ is positively impacted by 'targeted' delivery of drug to the site of action, which lowers $M_{0}$, and by the smaller volume of liquid lining the lungs. This is often assumed to be on the order of $10-30 \mathrm{~mL}$ in the conducting airways. Figure 9 is a plot of solubility vs. dose in the conducting airways, $D_{c}$ for a range of pulmonary drugs. There is a band running through the plot which represents the critical solubility for $V_{0}=10-30 \mathrm{~mL}$, wherein drugs above this band have sufficient solubility to be dissolved (i.e., $D o<$ $<1.0$ ), and drugs below the band are dissolution limited $(D o>>1)$. Most of the currently marketed small molecule drugs for inhalation, including short-acting and long-acting bronchodilators and tobramycin, are not dissolution limited. For these drugs, the extent of absorption is approximately 1.0, and is not limited by particle dissolution or permeability. As a rule of thumb, lipophilic drugs with a $\log \mathrm{P}>0$ are rapidly absorbed via the transcellular route with an absorption time of ca., $1 \mathrm{~min}$. In contrast, hydrophilic drugs with a $\log \mathrm{P}<0$ are absorbed via the paracellular route with an absorption time of ca., $1 \mathrm{~h}$ (Patton et al. 2004).

In contrast, there are two main classes of drugs that are dissolution limited. For potent inhaled corticosteroids with a nominal dose less than $1 \mathrm{mg}$, dissolution becomes important when drug solubility is $<1 \mu \mathrm{g} / \mathrm{mL}$ (e.g., fluticasone propionate, mometasone furoate, and beclomethasone dipropionate). As well, high dose antiinfectives with a nominal dose $>1 \mathrm{mg}$, become dissolution limited when the solubility $<100 \mu \mathrm{g} / \mathrm{mL}$ (e.g., ciprofloxacin betaine, amphotericin B). That is, in the lungs, dissolution limited drugs meet the standard definition of being 'insoluble' (Merck Index definition of insoluble is $<100 \mu \mathrm{g} / \mathrm{mL}$ ). The impact of inhaled corticosteroid solubility on mean dissolution time was studied by Högger et al. (Högger et al. 1994) (Table 4). Corticosteroids with a solubility on the order of $0.1 \mu \mathrm{g} / \mathrm{mL}$ and $>10$ exhibit significant increases in mean dissolution time relative to drugs with greater solubility and $D o<1$. Similarly, Forbes et al. (Forbes et al. 2015) noted a clear correlation between solubility and mean absorption time in man for these compounds.

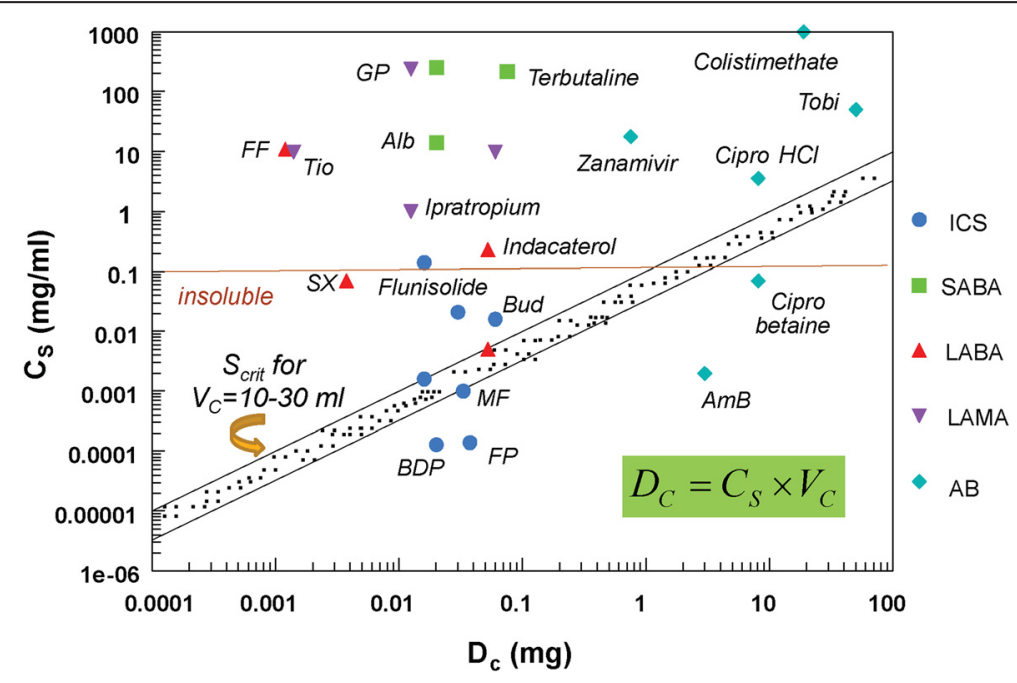

Fig. 9 Solubility of pulmonary drugs vs. the required dose in the conducting airways 
Table 4 Impact of solubility on mean dissolution time of inhaled corticosteroids

\begin{tabular}{lccc}
\hline Drug & $\mathrm{C}_{\mathrm{S}}(\mu \mathrm{g} / \mathrm{ml})$ & Do & $\begin{array}{c}\text { Mean Dissolution } \\
\text { Time }(\mathrm{hr})\end{array}$ \\
\hline Fluticasone propionate & 0.14 & 27 & $>8$ \\
$\begin{array}{l}\text { Beclomethasone } \\
\text { dipropionate }\end{array}$ & 0.13 & 15 & $>5$ \\
$\begin{array}{l}\text { Budesonide } \\
\text { Flunisolide }\end{array}$ & 16 & 0.375 & $\sim 0.1$ \\
\hline
\end{tabular}

For drugs that are dissolution limited, the extent of drug absorption into the systemic circulation is dependent on the pattern of regional deposition in the lungs. Relative to healthy volunteers, patients with obstructive lung disease will have a more central distribution of drug within the lungs. This results in increased mucociliary clearance and decreased systemic bioavailability (Brutsche et al. 2000). The observed dependence of regional deposition and systemic absorption on particle clearance makes establishing IVIVC via in vitro dissolution testing challenging for dissolution-limited drugs.

The rate of particle dissolution is related to Amidon's Dissolution Number, $D n$ (Amidon et al. 1995). $D n$ is given by:

$$
D n=t_{r e s} \cdot 3 D C / \rho r_{0}^{2}
$$

Where $t_{\text {res }}$ is the mean residence time, $D$ is the diffusion coefficient, $\rho=$ particle density, and $r_{0}$ is the particle radius. For oral drugs, $r_{0}$ is assumed to be $25 \mu \mathrm{m}$. In contrast, pulmonary drugs must have a $r_{0}<2.5 \mu \mathrm{m}$ in order to achieve effective delivery as an aerosol into the lungs. The ten-fold decrease in size results in 100-fold increases in $D n$. The impact of particle size on dissolution and resulting absorption rate and subsequent peak plasma concentration $\left(\mathrm{C}_{\max }\right)$ can be illustrated by the 2fold increase in peak plasma concentration $\left(C_{\max }\right)$ observed for a poorly soluble selective glucocorticoid modulator (SGRM) as primary particle size decreased from $3.1 \mu \mathrm{m}$ to $1.3 \mu \mathrm{m}$ (Olsson \& Bäckman 2014). Significant increases in $D n$ for pulmonary drugs are also observed, especially for formulations comprising spraydried or spray-freeze dried particles, as a result of decreases in particle density and/or increases in 'apparent' solubility when an amorphous physical form is created (Duddu et al. 2002; Almeida e Sousa et al. 2015; Weers \& Tarara 2014). For example, large increases in surface area can be achieved via control of particle morphology (i.e., creating nanostructured micron-sized particles) (Duddu et al. 2002; Weers \& Tarara 2014). The converse is also possible. Decreases in particle dissolution can be achieved by utilization of the neutral or zwitterionic form of a drug with decreased solubility. In this regard, ciprofloxacin $\mathrm{HCl}$ has a lung half-life in rats of $0.8 \mathrm{~h}$ following intratracheal administration, while the zwitterionic form at neutral $\mathrm{pH}$ has a decreased solubility and a half-life of $13.5 \mathrm{~h}$ (Endermann et al. 2011). The increased lung residence time results in significant reductions in colony forming units of Pseudomonas aeruginosa in the lungs of these animals.

\section{Particle dissolution in the lung: In vitro dissolution testing}

The basic principles of particle dissolution in the lungs was followed by Jason McConville (University of New Mexico, USA) explaining that in vitro dissolution testing for powders formulated for lung application will more than likely differ from procedures applied for dissolution testing of oral formulations and therefore will still only approximate the in vivo situation. For example, when one considers the complex dissolution environment of the GI tract is not completely reflected in the standardized conditions that are used for in vitro testing of pharmaceutical products in the laboratory. Dissolution of inhalation powders is potentially a critical component of the iBCS puzzle, and so standardized test methodology should be carefully considered. Figure 10 compares some factors considered for the dissolution of oral products compared to those necessary for inhaled products, assuming sink conditions. Note that it is anticipated that the dissolution rate of poorly water soluble compounds delivered to the lung will mainly be important in the peripheral regions of the lung and not in the central regions.

A principle method development consideration must be how to reproducibly present the particles to the dissolution test apparatus. There are some specific problems related to inhalation powders that are of concern (e.g., aggregation due to electrostatic interactions). Table 5 summarizes some of the areas of concern for dissolution in the lungs vs. in the GI tract.

\section{Published approaches for aerosol particle dissolution}

When dissolution is used as a research tool it is important to reflect on the goal of the test. Before any type of IVIVC can be considered it must be realized that the dissolution test is used to make a comparison between formulations under standardized conditions. As such, any test must be sufficiently reproducible so as to provide confidence in the results. With this in mind, a test should also be easy to set up and easy to use.

Multiple methods have been applied in an attempt to create a reproducible dissolution test for dispersed powder systems (Barakat et al. 2015; Davies \& Feddah 2003; Jaspart et al. 2007; May et al. 2014; May et al. 2012; McConville et al. 2000; Riley et al. 2012; Son et al. 2010; 


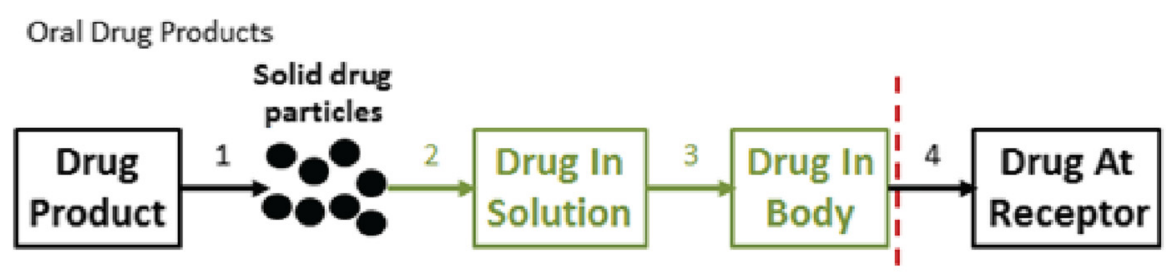

1 = Disintegration 2 = Dissolution $3=$ Drug Absorption $4=$ Drug Distribution/Absorption

Inhaled Drug Products

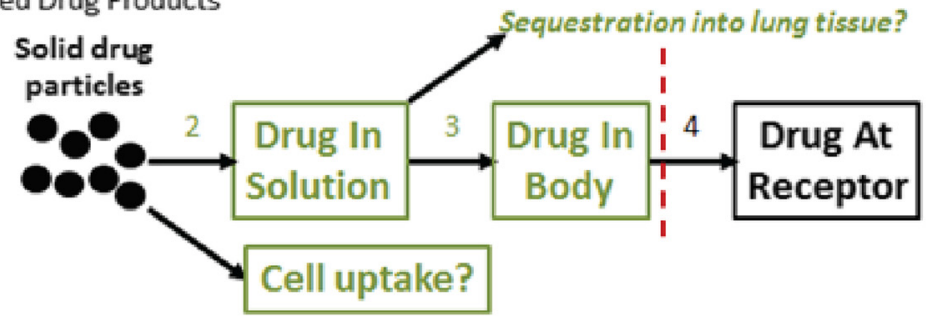

Fig. 10 The fate of oral vs. inhaled drug products in the body

Son \& McConville 2009). One previously published method (McConville et al. 2000), the first to employ the use of an impactor/impinger, describes dispersing powder onto an air-liquid interface and evaluating drug dissolution into a specially designed dissolution reservoir. The apparatus comprised a modified twin stage liquid impinger with an enlarged Stage 1 base. Powder that was above the specified $4.7 \mu \mathrm{m}$ particle cut-off impinged on an air-water interface, and dissolution of salbutamol from controlled release formulations was evaluated using a flow through detector. The method described was simply used for formulation comparison and was not designed to 'mimic' any conditions of the lung, and as described, the large particle sizes were only assessed leaving the $<4.7 \mu \mathrm{m}$ fraction to be evaluated only as a fine particle mass. Salama et al. describe a similar method that makes use of a modified Franz diffusion apparatus incorporating a heated membrane holder at its surface and a heated dissolution reservoir containing phosphate buffered saline at $\mathrm{pH}$ 7.4. Drug formulations can be placed onto a membrane before inserting into the membrane holder, in this way an air-liquid interface is maintained as drug diffuses into the reservoir for analysis (Salama et al. 2008).
Davies and Feddah (Davies \& Feddah 2003) presented a method that utilized a flow through dissolution approach after impaction of an aerosol powder onto a filter. In this approach the authors made use of an NGI apparatus and positioned a filter at the base of the USP throat. Powder collected on the filter was then sealed into flow-through holder. An HPLC pump was used to flow dissolution media through the filter until the entire drug had been removed for analysis, allowing for the construction of a cumulative release dissolution profile. This technique again made use of the oversized powder fraction, but in this case it was dispersed with the fine powder fraction.

Jaspart (Jaspart et al. 2007) described a method where powder was sealed within a filter membrane and immersed within the basket of a Type I dissolution apparatus. This method demonstrates some issues related to the contact area of a powder and as such is most likely suited to high solubility drug products.

A recent method also made use of the NGI apparatus by collecting powder dispersed into each collection stage either onto a polycarbonate membrane (Son \& McConville 2009), or directly onto the stainless steel collection base (Son et al. 2010). With either powder collection

Table 5 Considerations for different organ target sites

\begin{tabular}{ll}
\hline Gl Tract Considerations & Lung Considerations \\
\hline SA of dose important (for disintegration) & Dose has large SA \\
Large SA for absorption & Large SA for dissolution/abs. \\
High Liquid volume & Low liquid volume \\
$\mathrm{pH} 1-8$ & $\mathrm{pH} 6-7$ \\
Rel. High hydrodynamic conditions & Rel. Low hydrodynamic conditions \\
& Macrophage interaction \\
\hline
\end{tabular}


method the specified powder cut from each stage was covered with a large pore polycarbonate membrane and placed in its own Type II dissolution apparatus vessel (either large volume or small volume). The dissolution media could be collected at intervals in the normal way and analyzed to construct a dissolution profile. The latter method adopting the use of the stainless steel impaction base demonstrated the most reproducible method for the Type II apparatus to date.

Overall, standard dissolution methods can be adapted for a variety of formulation types, and previous studies have shown that dosage form presentation to the dissolution method chosen is a key component in determining reproducibility. Reproducibility for comparative purposes is critical for both $R \& D$ and quality control. Once there is an established methodology to address this shortfall, then IVIVC studies may follow.

Additionally, although a dissolution method may be designed to reasonably represent actual particle dissolution on a representative airway mucosa, it is still unclear if we must take into consideration the balance between dissolution and absorption and how this changes from the very permeable peripheral regions of the lung to the less permeable conductive airways. Hence, it is possible that non-sink conditions encountered in the conductive airway means observed dissolution-related changes are unrelated to, for example, peak plasma concentration.. Thus, to understand the clinical relevance of an in vitro dissolution profile we must understand deposition pattern, particle clearance, local permeability, tissue sequestration and absorption into the systemic circulation.

\section{Permeability, absorption and PK/PD in the lung}

Following deposition and dissolution in the lung, aerosol drugs are absorbed through the pulmonary membrane barriers primarily by diffusion and possibly via transporters (Patton et al. 2004; Sakagami \& Gumbleton 2011). Masahiro Sakagami (Virginia Commonwealth University, USA) presented this session and the summary provided includes commentary from Guenther Hochhaus (University of Florida, USA) and Per Bäckman (AstraZeneca, Sweden). For dissolved low molecular weight drugs, the intrinsic lung absorption rates are generally fast with absorption half-lives of $\leq 1 \mathrm{~h}$, irrespective of lipophilicity or involvement of transporters. Exceptions to this generalized behavior arise when there is sustained binding to, or slow dissociation from, the lung membrane components including target proteins (e.g., LABAs and LAMAs), or intracellular trapping (e.g., fatty acid esterification and basic amines) (Patton et al. 2004; Sakagami \& Gumbleton 2011; Anderson et al. 1994; Casarosa et al. 2009; Edsbäcker \& Brattsand 2002; Lasic et al. 1995). These intrinsic kinetic properties of lung absorption/permeability can be reasonably studied using in vitro lung epithelial cell monolayer systems, such as Calu-3 cells (Forbes \& Ehrhardt 2005; Mathia et al. 2002), in a manner similar to how the Caco-2 cell system is utilized for classification of intestinal absorption. Permeability values are well-correlated with the in vivo rate constants $(\mathrm{ka})$ for lung absorption in animals (Forbes \& Ehrhardt 2005; Mathia et al. 2002), which likely makes them useful in rank-ordering and screening drugs with respect to their intrinsic lung absorption rates. Even so, deriving inhalation BCS class boundaries to classify high or low lung absorption/permeability from these in vitro lung epithelial cell systems would not be simple. In vivo ka values are time-dependent and thus, it is likely that the observed initial ka values largely reflect rapid absorption from the peripheral lung. Ideally, an iBCS model for absorption/permeability should be predictive for the region of clinical interest, yet is in reality a challenge, given that this is poorly defined in most cases and that absorption from the more central regions of the lung cannot be easily determined. To further complicate the situation, in the lung, absorptive elimination is in kinetic competition with non-absorptive elimination, mainly by mucociliary clearance from the upper regions of the lung, as illustrated in Fig. 11 (Olsson \& Bäckman 2014). Hence, the performance of inhaled drugs, such as local therapeutic lung effects and systemic adverse events, depends not only on these intrinsic absorption/permeability properties but also on aerosol formulation/device, delivery and drug dissolution properties in determination of their PK/PD profiles. In addition, it should be noted that lung targeting may also be improved by high systemic (hepatic) clearance and low oral bioavailability, which both reduce the degree of systemic exposure (Tayab \& Hochhaus 2005; Weber \& Hochhaus 2013).

The competitive nature of lung disposition was clinically seen, when beclomethasone dipropionate (BDP) was reformulated from a CFC to a HFA metered dose inhaler (MDI) product (Leach et al. 1998). Smaller-size aerosol delivery from the HFAbased solution MDI was capable of greater lung peripheral deposition and local PD effects, compared to the CFC-based suspension MDI (Leach et al. 1998). Likewise, as described in an earlier section, a poorly soluble and highly permeable, selective glucocorticoid receptor modulator (SGRM) demonstrated more than a 2 -fold change in $\mathrm{PK}$ profiles $\left(\mathrm{C}_{\max }\right.$ and AUC) in humans following inhaled delivery from different dry powder inhalers and nebulizers. This was attributed by the authors to be a result of differences in dissolution rate and regional lung deposition (Leach et al. 1998). Therefore, during preclinical development of inhaled drugs, it is not surprising that both 


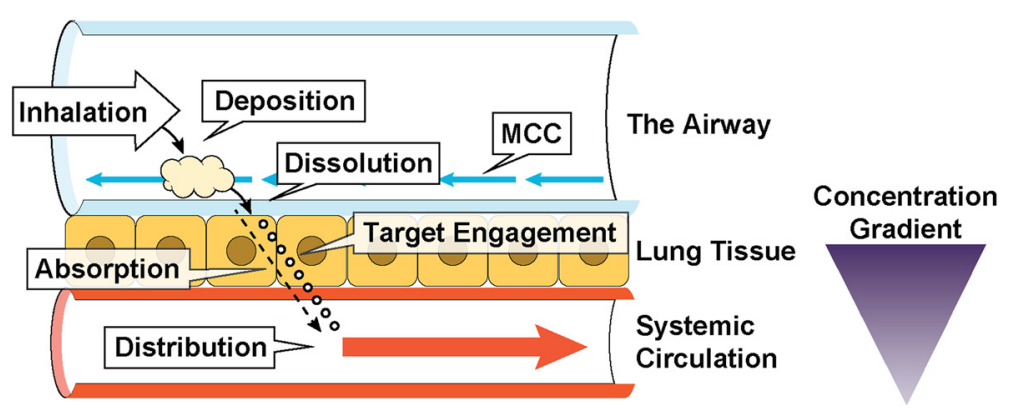

Fig. 11 Lung disposition of pharmaceutical aerosol drugs following inhalation. MCC: mucociliary clearance. Adapted from (Olsson \& Bäckman 2014)

intrinsic and aerosol formulation/device- delivery-, and drug dissolution-controlled PK properties must be considered to optimize a drug's local or systemic PD effects (e.g., potency and duration of effect). In this context, lung disposition in animals like rats and dogs, but perhaps not mice, rabbits and guinea pigs are often kinetically equivalent to that in humans (Patton et al. 2004; Sakagami \& Gumbleton 2011), especially for highly soluble and well absorbed low molecular weight drugs. In fact, Ferguson (Ferguson 2010) reported that the lung absorption ka values for such drugs like terbutaline and rofleponide in rats and dogs enabled prediction of the PK profiles in humans with a reasonable degree of confidence, assuming their complete lung absorption. Moreover, with a given pulmonary administration, animal models are also capable of assessing "drug in formulation" effects on PK/PD outcomes such as local lung PD actions via receptor binding and occupancy determination (Suarez et al. 1998; Talton et al. 2000). However, aerosol delivery has commonly resulted in greater lung absorption and local/systemic PD effects in animals, compared to forced lung dosing methods like instillation (Brown \& Schanker 1983; Niven et al. 1995). Thus, regional lung deposition control is essential in animal studies, yet its relevance to PK/PD outcomes for aerosol drugs generated from inhaler devices in humans still remains to be established.

Compartmental PK/PD modeling simulations can be very helpful to better understand the complex interplay of deposition, clearance, dissolution and absorption. For instance, it has been suggested that factors increasing the lung residence time, such as slow dissolution, low permeability/slow absorption, and intracellular trapping, increase pulmonary targeting of drugs following inhalation (Tayab \& Hochhaus 2005; Weber \& Hochhaus 2013). In addition, as mucociliary clearance functions only in the upper regions of the lung, an optimal dissolution rate to maximize such pulmonary targeting was also identified (Tayab \& Hochhaus 2005; Weber \& Hochhaus 2013). Given these notions, more realistic compartmental lung disposition kinetic models have been recently developed for poorly soluble corticosteroids, incorporating regional lung (i.e., central and peripheral) deposition, dissolution rate-controlled absorption and mucociliary clearance (Tayab \& Hochhaus 2005; Sakagami 2014; Weber \& Hochhaus 2015). The models resulted in plausible successes in fitting/ simulating and describing different PK profiles of poorly soluble fluticasone propionate (FP) formulated in various inhaler products, while yielding its lung regionindependent, dissolution-controlled slow absorption rate with a half-life of $\sim 3.5 \mathrm{~h}$ (Tayab \& Hochhaus 2005; Sakagami 2014; Weber \& Hochhaus 2015). In line with these results, a further study has now implied that in vitrobased mean dissolution times may be an indicator for the in vivo lung absorption rates of slowly-dissolving, lipophilic corticosteroids (e.g., FP, ciclesonide and budesonide) (Rohrschneider et al. 2015). Meanwhile, PKlinked systemic PD modeling was found feasible for inhaled FP to predict the profiles of serum cortisol reduction, as potential systemic adverse outcomes (Meibohm et al. 1999; Möllmann et al. 1998). However, PK-linked local PD modeling remains theoretical for inhaled corticosteroids in humans, due to a lack of appropriate measurable local PD markers, as have been also the cases for inhaled bronchodilators (Gaz et al. 2012; Hochhaus et al. 1997).

Mechanistic computer-based modeling may also be used to provide better understanding on how deposition, dissolution, clearance, absorption and systemic disposition influence the clinical performance of an inhaled product. In a recent example, a mechanistic model was applied to predict systemic exposure following inhaled administration of SGRM in healthy volunteers using six different devices and formulation. Initial data show systemic exposure to be well predicted, as shown in Fig. 12 (Olsson \& Bäckman 2014), in contrast to the poor correlation between systemic exposure and predicted lung 


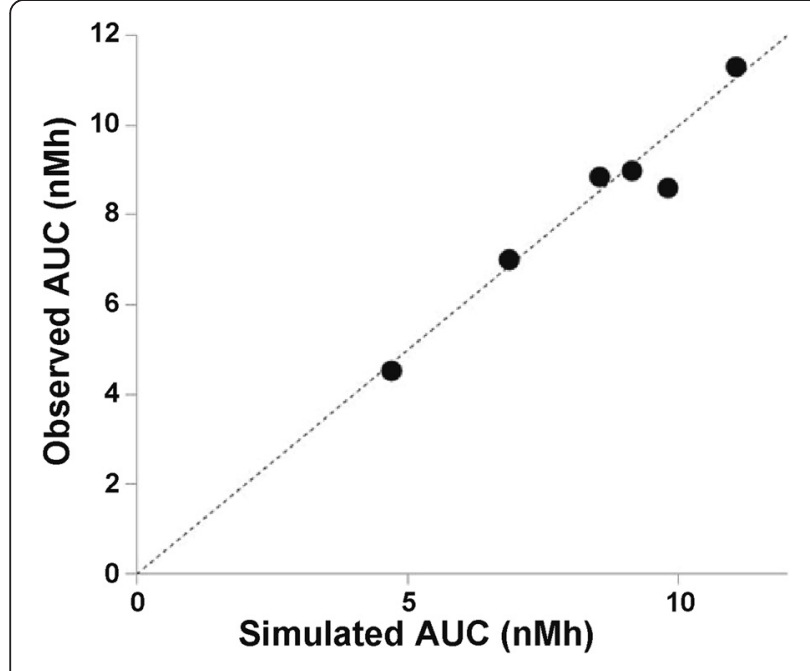

Fig. 12 Observed and predicted systemic exposure (AUC) following inhaled administration of SGRM using six different devices and formulations (12-18 healthy volunteers). The dashed line represents the identity line. Modified from (Olsson \& Bäckman 2014)

dose shown in Fig. 6, above. Further evaluation of the results has also demonstrated that the shape of the plasma PK profile was well predicted, thereby providing useful insights into the fate of the drug deposited in different lung regions [AstraZeneca, data on file].

\section{Case studies}

Following the presentation of background information, three case studies were presented to provide some possible food for thought as to where having an iBCS might take us, at least with respect local therapy. Bäckman presented clinical PK data and mechanistic modeling data on a selective glucocorticoid modulator Hochhaus presented some thoughts on how this might work for an ICS, and Niven extended the discussion to atypical molecules. The following summarizes those discussions.

Clinical PK data comparing systemic exposure of a lipophilic selective glucocorticoid receptor modulator in healthy volunteers after administration in six different inhalation formulations and devices was shown to correlate better with peripheral lung dose than with total lung dose or total delivered dose. Also, the rate and extent of absorption from lung after inhalation was shown to be well predicted by deposition pattern in combination with the expected rate of mucociliary clearance and rate of dissolution in situ as simulated by a computer based mechanistic model. Taken together these observations indicate: (i) that the bioavailability of this compound depends on intra pulmonary deposition pattern and; (ii) that dissolution is the rate limiting step governing the systemic absorption rate for this lipophilic drug. Given that solubility of inhaled glucocorticoids is related to mean absorption time in man (May et al.
2014), this observation can probably be generalized to all inhaled drugs with low water solubility, as discussed above. Hence, it is concluded that rate of dissolution is an important predictor of clinical performance for this class of compounds and that a BCS type of classification could provide an important aid to both compound and product design, if qualified by dose and regional deposition pattern.

When taking an analogy to the giBCS model (Varma et al. 2004) lung absorption/permeation properties for inhaled drugs/products can be potentially classified with the absorption number (An), which can be defined as the ratio of mean residence time to mean absorption time in the lung. However, both of these temporal parameters are lung region-dependent and thus, should ideally be determined for the region(s) of clinical interest, which is difficult, as we currently lack appropriate experimental methods to make this assessment. Besides, in the giBCS model, mean residence time is fixed at $180 \mathrm{~min}$, yet its definition and value in the lung are uncertain. Even so, for locally-acting drugs, it is notable to recognize that many recent successes appear to arise out of deviation from giBCS Class I characteristics, i.e., slow dissolution (e.g., FP and ciclesonide) and slow intrinsic permeation/absorption through sustained binding or intracellular trapping (e.g., LABAs, LAMAs, budesonide, and possibly, tiotropium and olodaterol) (Anderson et al. 1994; Casarosa et al. 2009; Edsbäcker \& Brattsand 2002; Lasic et al. 1995; Borghardt et al. 2014; Parra-Guillen et al. 2014). This suggests that slow dissolution rate and low absorption numbers are favorable for locally-acting low molecular weight drugs, as this combination provides sufficient lung retention to achieve the desired local pharmacological effects without rapid absorption/ disappearance from the lung. The implementation of an iBCS approach may therefore facilitate engineering such properties into the development pipeline.

\section{Conclusions}

Historically, the lungs have offered a unique opportunity to target drugs for local action and more recently have been considered a potential route for systemic delivery. Biopharmaceutical factors influencing drug disposition and efficacy have been known generally for several decades. However, a systematic framework describing the contribution of each of the elements of the drug and delivery system physical chemistry, lung physiology, anatomy, cell biology, biophysics and biochemistry to performance has been an elusive objective.

This workshop was held to determine if a systematic framework to classify pulmonary drugs could be established, and if so, what the scope and relevance of such a classification approach would be. Considerations were: lung physiology and the fate of inhaled drugs, regional 
aerosol deposition, macroscopic clearance mechanisms, particle dissolution, drug permeability and absorption. The interplay of these attributes on pharmacokinetics and pharmacodynamics was also discussed.

The giBCS was established when solubility and permeability of drug was shown to be predictive of bioavailability and efficacy. In contrast drugs of importance for lung delivery are subject to a series of rate constants not only at the microscopic scale but also at the macroscopic scale of clearance mechanisms. Whereas the GI accepts foreign materials for further processing, the lungs have a defense mechanism that is designed to reject or removes foreign materials in order to preserve gas exchange. Therefore, the lungs present a series of barriers to the entry of aerosol particles and droplets that the GI does not.

For particles small enough to enter the lung, at the macroscopic level, the branching airways act in synchrony with inspiratory airflow to facilitate airborne particulate capture regionally. Mucociliary clearance and cell mediated transport and absorption determine the fate of inhaled drugs. In the central airways, the main clearance mechanism is mucociliary clearance, while in the periphery clearance is governed by macrophage uptake and permeability/systemic absorption rates. Drug deposition, and therefore the dose to the various regions within the lung, is controlled by airway geometry, aerodynamic particle size distribution and inhaled flow rate. The overall concentration of drug in the lung is therefore dynamic and varies by region due to differences in "fluid" levels and clearance mechanisms. Peripheral deposition is on the order of $50 \%$ of the total lung dose.

As indicated, the residence time of drug deposited in different locations in the lungs depends upon the predominant clearance mechanism, which in turn depends on particle dissolution rate influencing its appearance in the molecular state. On a microscopic scale drug dissolution is required for drug presentation through mucus and airways fluid to the epithelium, ultimately reaching the target receptor and supporting the desired therapeutic action. Dose numbers for the central airways can be calculated assuming lung fluid volume in the central airways to be $10-30 \mathrm{~mL}$ and a regional dose of $50 \%$ of total lung dose. Based on these calculations, low solubility inhaled corticosteroids and large dose anti-infective agents may be dissolution limited. Inhaled corticosteroids with dose numbers greater than 10 have a mean dissolution time greater than those with dissolution numbers less than 1 . The particle size of inhaled drugs is, by necessity, much smaller than their oral counterparts. Therefore, the main approach to tuning the dissolution number is through formulation strategies. Dissolution test methods are currently nonstandardized for inhaled drugs and are not intended to provide IVIVC correlations. A common/standardized dissolution test method would benefit formulators for development purposes.

Local drug metabolism, the action of transporters, the rate of absorption, and receptor binding, modulate the duration of local action. The combined macro- and microscopic mechanism of disposition dictate the pharmacokinetics and overall pharmacodynamics and efficacy of the drug in the entire organ system. For locally acting pulmonary drugs, systemic blood levels are a measure of the drug in a compartment that is not associated with the site of action. Therefore, kinetics is more important than the overall extent of absorption.

The workshop concluded that unlike the GI, the dissolution rate is a more significant measure of drug availability in the lungs than solubility. The dose number for currently marketed inhaled drugs identified only a few solubility-limited compounds/classes and dissolution number can be modified through formulation approaches. For local action, permeability or the rate of absorption may only be relevant as a predictor of local residence time and, therefore, duration of effect since it reflects drug that is removed from the target site, with the notable exception of systemic disease therapy. Slow dissolution rate and a low absorption number are more favorable properties for locally-acting low molecular pulmonary drugs since this increases the residence time in the lung. This is counter to the giBCS model and demonstrates that a more accurate predictive model would require consideration of the other factors involved in drug disposition including site of deposition and specific clearance mechanisms and their rates of drug presentation to, and from, the intended target site.

The overall goal of this workshop was to determine whether or not an inhalation product biopharmaceutics classification system (iBCS) based on physicochemical properties of physiologic relevance could be developed for pulmonary drug products. It was not to develop the specific model or classification system. A classification system, once fully developed, would be a tool for the formulators and discovery chemists working in the pulmonary drug delivery field; it is not the intent to use such a model to obtain regulatory relief. From this perspective, it can be concluded that there is an opportunity to develop a model to classify pulmonary drugs based on physicochemical attributes specific to lung physiology and drug delivery and therefore the workshop met the intended goal.

\section{Endnotes}

${ }^{1}$ AAPS/FDA/USP Workshop: Inhalation Biopharmaceutical Product Classification System Development: Challenges and Opportunities, Baltimore, MD. 2015 March 16-17. 


\section{Abbreviations}

AAPS: American Association of Pharmaceutical Scientists; AB: Antibiotics; ALB: Albuterol; AMB: Amphotericin B; AN: Absorption Number; AUC: Area under the curve; BDP: Beclomethasone Dipropionate; BUD: Budesonide; $C_{\text {MAX: }}$ Peak drug concentration in pharmacokinetic study; $C_{S}$ : Solubility in water; D: Diffusion coefficient; $D_{c}$ : Dose in the central airways;

DN: Dissolution number; DO: Dose number; ENAC: Epithelial sodium channel; ET-1: Epithelial Type 1 cells; ET-2: Epithelial Type-2 Cells; FDA: Food \& Drug Administration; FF: Formoterol Fumarate; FP: Fluticasone Propionate; GIBCS: Gastrointestinal Biopharmaceutical CLASSIFICATION System; GP: Glycopyrronium; HPL: High performance liquid chromatography; IBCS: Inhalation biopharmaceutical classification system; ICS: Inhaled corticosteroid; IVIVC: in vitro-in vivo correlation; $\mathrm{K}_{\mathrm{A}}$ : Rate constant for lung absorption; LABA: Long-acting beta-agonist; LAMA: Long-acting muscarinic antagonist; LOG P: Octanol-water partition coefficient; $M_{0}$ : Mass of drug (I.E., 'DOSE') used in calculation of do; MDI: Metered dose inhaler; MDT: Mean dissolution time; MF: Mometasone furoate; MØ: Alveolar macrophages; NGI: Next generation impactor; P/C: Ratio of peripheral/Central deposition of drug in the lungs; PD: Pharmacodynamic; PK: Pharmacokinetic; PK PD: Pharmacokinetic / Pharmacodynamics correlations; $\mathrm{R}_{0}$ : Particle radius; SABA: Short acting beta-agonist; $\mathrm{S}_{\text {CRIT: }}$ Critical solubility limit for complete dissolution in epithelial lining fluid; SGRM: Selective glucocorticoid modulator; SP-A: Surfactant protein A; SP-B: Surfactant protein B; SPC: Surfactant protein C; SP-D: Surfactant protein D; SX: Salmeterol Xinafoate; TIO: Tiotropium; $T_{\text {RES: }}$ Residence time in the lungs; USP: United States Pharmacopeia; $V_{0}$ : Volume of epithelial lining fluid; $\rho$ : Density.

\section{Competing interests}

All authors declare that they are employees or owners of the companies/ institutions provided and therefore received payments from said companies/ institutions. Otherwise, the authors declare that they have no competing interests.

\section{Authors' contributions}

JEH and AH prepared the abstract, background, and conclusion sections. PM, $\mathrm{CML}$, and RN were primary authors of the Lung Physiology and the Fate of Inhaled Drugs discussion section. ARC was primary author of the pulmonary deposition and clearance section. JGW was primary author of the particle dissolution section. JM was primary author of the dissolution technology section. GH, MS, and PB were the primary authors of the PK/PD and case study sections. WD served as editor for the manuscript and organized all reference materials. PJK contributed to the deposition discussion and was responsible for formatting the manuscript figures for the authors. JEH introduced the iBCS concept and workshop within INTFG and lead much of the meeting organization and manuscript preparation. All authors read and approved the final manuscript.

\section{Acknowledgements}

The authors gratefully acknowledge the support and organization from AAPS INTFG executive committee members: Bill Schachtner (Lupin Pharmaceuticals, USA), Jeff Breit (Bend Research Inc., USA), and Sai Chamarthy (Merck R\&D, USA). Gordon Amidon (University of Michigan, USA), for his expert review of the history and development of the "giBCS" and guidance. Trish Smith, from AAPS, for her support in organizing the speakers and presentation materials.

\footnotetext{
Author details

${ }^{1}$ JDP Pharma Consulting, LLC, San Carlos, CA, USA. ${ }^{2}$ AstraZeneca R\&D, Mölndal, Sweden. ${ }^{3}$ Aerogen Pharma, San Carlos, CA, USA. ${ }^{4}$ Division of Pharmaceutical Analysis, Food and Drug Administration, Saint Louis, MO, USA. ${ }^{5}$ RTI International, RTP, Durham, NC, USA. ${ }^{6}$ University of Florida, Gainesville, FL, USA. 'Lovelace Respiratory Research Institute, Albuquerque, NM, USA. ${ }^{8}$ Helmholtz-Institute for Pharmaceutical Research Saarland (HIPS) and Saarland University, Saarbrücken, Germany. ${ }^{9}$ Merck Research Laboratories, Rahway, NJ, USA. ${ }^{10}$ University of New Mexico, Albuquerque, NM, USA. ${ }^{11}$ Novartis, San Carlos, CA, USA. ${ }^{12}$ Virginia Commonwealth University, Richmond, VA, USA.
}

Received: 8 October 2015 Accepted: 17 November 2015 Published: 27 February 2016

\section{References}

Agnew J, Sutton P, Pavia D, Clarke S (1986) Radiological assessment of mucociliary clearance: towards a definition of a normal range. $\mathrm{Br} J$ Radiol 59:147-51

Albertine KH (2010). In: Mason RJ, Broaddus VC, Martin T et al. (eds) Murray and Nadel's Textbook of Respiratory Medicine, 5th edn. Saunders Elsevier, Waltham, MA

Almeida e Sousa L, Reutzel-Edens S, Stephenson G, Taylor L (2015) Assessment of the "amorphous" solubility of a group of diverse drugs using new experimental and theoretical approaches. Mol Pharm 12(2):484-95

Amidon GL, Lennernas H, Shah VP, Crison JR (1995) A Theoretical Basis for a Biopharmaceutical Drug Classification: The Correlation of in Vitro Drug Product Dissolution and in Vivo Bioavailability. Pharm Res 12:413-20

Anderson G, Lindén A, Rabe K (1994) Why are long-acting beta-adrenoceptor agonists long-acting? Eur Respir J 7:569-78

Barakat A, Krämer J, de Souza CC, Lehr C-M (2015) In vitro-in vivo correlation: Shades on some non-conventional dosage forms. Dissolution Technology 22(2):19-22

Bastacky J, Lee CY, Goerke J, Koushafar H, Yager D, Kenaga L, Speed TP, Chen Y, Clements JA (1995) Alveolar lining layer is thin and continuous: low-temperature scanning electron microscopy of rat lung. J Appl Physiol (1985) 79(5):1615-28

Borghardt J, Weber B, Staab A, Kunz C, Schiewe J, Kloft C (2014) The physiological interpretation of population pharmacokinetic modelling results for inhaled olodaterol. Paper presented at the Annual Meeting of the Population Approach Group in Europe, Alicante, Spain

Brown RJ, Schanker L (1983) Absorption of aerosolized drugs from the rat lung. Drug Metab Dispos 11(4):355-60

Brutsche MH, Brutsche IC, Munawar M, Langley SJ, Masterson CM, DaleyYates PT, Brown R, Custovic A, Woodcock A (2000) Comparison of pharmacokinetics and systemic effects of inhaled fluticasone propionate in patients with asthma and healthy volunteers: a randomised crossover study. Lancet 356(9229):556-61

Casarosa P, Bouyssou T, Germeyer S, Schnapp A, Gantner F, Pieper M (2009) Preclinical evaluation of long-acting muscarinic antagonists: comparison of tiotropium and investigational drugs. J Pharmacol Exp Ther 330:660-8

Clark A (2010) Beyond the throat: Preferred methods of assessing regional distributions in the lung. In: Dalby R, Byron P, Peart J, Farr S (eds) Respiratory Drug Delivery VIII, Orlando, FL, 2010. Davis Harwood International Publishing, Raleigh, NC, pp 235-44

Clark A (2012) Understanding penetration index measurements and regional lung targeting. J Aerosol Med Pulm Drug Deliv 25(4):179-87

Clark A (2015) Limitations of Pulmonary Drug Delivery

Clark A, Eldon M, Dwivedi S, Wolff R (2006) The application of pulmonary inhalation technology to drug discovery. Annual Reports in Medicinal Chemistry 41:383-93

Crapo JD, Barry BE, Gehr P, Bachofen M, Weibel ER (1982) Cell number and cell characteristics of the normal human lung. Am Rev Respir Dis 126(2):332-7

Davies N, Feddah M (2003) A novel method for assessing dissolution of aerosol inhaler products. Int J Pharm 255(1-2):175-87

de Souza CC, Daum N, Lehr CM (2014) Carrier interactions with the biological barriers of the lung: advanced in vitro models and challenges for pulmonary drug delivery. Adv Drug Deliv Rev 75:129-40

Duddu S, Sisk S, Walter Y, Tarara T, Trimble K, Clark A, Eldon M, Elton R, Pickford M, Hirst P, Newman S, Weers J (2002) Improved lung delivery from a passive dry powder inhaler using an engineered PulmoSphere ${ }^{\circledast}$ powder. Pharm Res 19:689-95

Edsbäcker S, Brattsand R (2002) Budesonide fatty-acid esterification: a novel mechanism prolonging binding to airway tissue. Review of available data. Ann Allergy Asthma Immunol 88:609-16

Eixarch H, Haltner-Ukomadu E, Beisswenger C, Bock U (2010) Drug Delivery to the Lung: Permeability and Physicochemical Characteristics of Drugs as the Basis for a Pulmonary Biopharmaceutical Classification System (pBCS). J Epithelial Biology \& Pharmacology $3: 1-14$

Endermann R, Labischinski H, Ladel C, Petersen U, Newton B (2011) Treatment of bacterial disease of the respiratory organs. United States Patent 8034817, 11 Oct 2011.

Ferguson D (2010) The challenges of PKPD modelling for inhaled delivery. Paper presented at the The academy of Pharmaceutical Sciences: Biopharmaceutics of Inhaled Drug Delivery. APSGB 2nd International Workshop, Stevenage, UK

Forbes B, Ehrhardt C (2005) Human respiratory epithelial cell culture for drug delivery applications. Eur J Pharm Biopharm 60:193-205

Forbes B, Bäckman P, Christopher D, Dolovich M, Li B, Morgan B (2015) In vitro testing of orally inhaled products: Development of science-based regulatory approaches. AAPSJ 17(4):837-52 
Gaz C, Cremona G, Panunzi S, Patterson B, De Gaetano A (2012) A geometrical approach to the PKPD modelling of inhaled bronchodilators. J Pharmacokinet Pharmacodyn 39:415-28

Gehr P, Bachofen M, Weibel ER (1978) The normal human lung: ultrastructure and morphometric estimation of diffusion capacity. Respir Physiol 32(2):121-40

Hansen JE, Ampaya EP (1974) Lung morphometry: a fallacy in the use of the counting principle. J Appl Physiol 37(6):951-4

Hastedt J (2014) The Lung as a Dissolution Vessel? Inhalation 8(6):18-22

Hickey AJ, Thompson DC (1992) Physiology of the airways. In: Hickey AJ (ed) Pharmaceutical Inhalation Aerosol Technology. Marcel Dekker, New York, pp 1-27

Hittinger M, Juntke J, Kletting S, Schneider-Daum N, de Souza CC, Lehr CM (2015) Preclinical safety and efficacy models for pulmonary drug delivery of antimicrobials with focus on in vitro models. Adv Drug Deliv Rev 85:44-56

Hochhaus G, Möllmann H, Derendorf H, Gonzalez-Rothi R (1997) Pharmacokinetic/pharmacodynamic aspects of aerosol therapy using glucocorticoids as a model. J Clin Pharmacol 37:881-92

Högger P, Bonsmann U, Rohdewald P (1994) Efflux of glucocorticoids from human lung tissue to human plasma in vitro. Eur Respir J 7:382s

Jaspart S, Bertholet P, Piel G, Dogne J, Delattre L, Evrard B (2007) Solid lipid microparticles as a sustained release system for pulmonary drug delivery. Eur J Pharm Biopharm 65(1):47-56

Klein SG, Hennen J, Serchi T, Blomeke B, Gutleb AC (2011) Potential of coculture in vitro models to study inflammatory and sensitizing effects of particles on the lung. Toxicol In Vitro 25(8):1516-34

Kolaca C, Streichhanr P, Lehr C-M (1996) Oral Bioavailability of Proteolytic Enzymes. Eur J Pharm Biopharm 42(4):222-32

Lasic D, Ceh B, Stuart M, Guo L, Frederik P, Barenholz Y (1995) Transmembrane gradient driven phase transition within vesicles: lessons for drug delivery. Biochemica et Biophysica Acta 1239:145-56

Leach CL, Davidson PJ, Boudreau RJ (1998) Improved airway targeting with the CFC-free HFA-beclomethasone metered-dose inhaler compared with CFCbeclomethasone. Eur Respir J 12(6):1346-53

Lippman M (1977) Regional deposition of particles in the human respiratory tract. In: Lee DHK, Falk HL, Murphy SD (eds) Handbook of Physiology: Reaction to environmental agents, Reaction to environmental agents. Lippincott Williams and Wilkins, Bethesda MD

Mathia N, Timoszyk J, Stetsko P, Megill J, Smith R, Wall D (2002) Permeability characteristics of calu-3 human bronchial epithelial cells: in vitro-in vivo correlation to predict lung absorption in rats. J Drug Target 10:31-40

May S, Jensen B, Wolkenhauer M, Schneider M, Lehr C (2012) Dissolution Techniques for In Vitro Testing of Dry Powders for Inhalation. Pharm Res 29(8):2157-66

May S, Jensen B, Weiler C, Wolkenhauer M, Schneider M, Lehr C-M (2014) Dissolution Testing of Powders for Inhalation: Influence of Particle Deposition and Modeling of Dissolution Profiles. Pharm Res 31(11): 3211-24

McConville JT, Patel N, Ditchburn N, Tobyn MJ, Staniforth JN, Woodcock P (2000) Use of a novel modified TSI for the evaluation of controlled-release aerosol formulations. Drug Dev Ind Pharm 26(11):1191-8

Meibohm B, Hochhaus G, Möllmann H, Barth J, Wagner M, Krieg M, Stöckmann R, Derendorf H (1999) A pharmacokinetic/ pharmacodynamics approach to predict the cumulative cortisol suppression of inhaled corticosteroids. J Pharmacokinet Pharmacodyn 27(2):127-47

Moffet D, Moffet S, Schauf C (1993) Human physiology: foundation and frontiers, 2nd edn. Mosby-Year Book, St. Louis

Möllmann H, Wagner M, Meibohm B, Hochhaus G, Barth J, Stöckmann R, Krieg M, Weisser H, Falcoz C, Derendorf H (1998) Pharmacokinetic and pharmacodynamic evaluation of fluticasone propionate after inhaled administration. Eur J Clin Pharmacol 53(6):459-67

Newman S, Hirst P, Pitcairn G, Clark A (1998) Understanding regional lung deposition data in gamma scintigraphy. In: Dalby $R$, Byron P, Farr $S$ (eds) Respiratory Drug Delivery VI, Hilton Head, SC, 1998. Interpharm Press, Buffalo Grove, NY, pp 9-16

Niven R, Whitcomb K, Shaner L, Ip A, Kinstler O (1995) The pulmonary absorption of aerosolized and intratracheally instilled rhG-CSF and monoPEGylated rhGCSF. Pharm Res 12:1343-9

Olsson B, Bäckman P (2014) Mouth-throat models for realistic in vitro testing: A proposal for debate. In: Dalby R, Byron P, Peart J et al (eds) Respiratory Drug
Delivery 2014, Fajardo, Puerto Rico, 2014. DHI Publishing, LLC, River Grove, II, pp 287-894

Olsson B, Bondesson E, Borgstrom L, Edsbacker S, Eirefelt S, Ekelund K (2011) Pulmonary drug metabolism, clearance and absorption. In: Smyth HDC, Hickey AJ (eds) Controlled Pulmonary Drug Delivery 21 Advances Delivery Science and Technology. Controlled Release Society.

Parent R (1982) Comparative biology of the normal lung, vol 1. CRC press, Boca Raton

Parra-Guillen Z, Weber B, Sharma A, Freijer J, Retlich S, Borghardt J et al (2014) Population pharmacokinetic analysis of tiotropium in healthy volunteers after intravenous administration and inhalation. J Pharmacokinet Pharmacodyn 41: S54

Patton J, Fishburn C, Weers J (2004) The lungs as a portal of entry for systemic drug delivery. Proc Am Thorac Soc 1:338-44

Patton JS, Brain JD, Davies LA, Fiegel J, Gumbleton M, Kim KJ, Sakagami M, Vanbever R, Ehrhardt C (2010) The particle has landed-characterizing the fate of inhaled pharmaceuticals. J Aerosol Med Pulm Drug Deliv 23(Suppl 2):S71-87

Riley T, Christopher D, Arp J, Casazza A, Colombani A, Cooper A, Dey M, Maas J, Mitchell J, Reiners M, Sigari N, Tougas T, Lyapustina S (2012) Challenges with developing in vitro dissolution tests for orally inhaled products (OIPS). AAPS PharmSciTech 13:978-89

Rohrschneider M, Bhagwat S, Krampe R, Michler V, Breitkreutz J, Hochhaus G (2015) Evaluation of the transwell system for characterization of dissolution behavior of inhalation drugs: effects of membrane and surfactant. Mol Pharm 12:2618-24

Ruge CA, Kirch J, Lehr CM (2013) Pulmonary drug delivery: from generating aerosols to overcoming biological barriers-therapeutic possibilities and technological challenges. Lancet Respir Med 1(5):402-13

Sakagami M (2014) Fluticasone pharmacokinetics: meta-analysis and models. In: Dalby R, Byron P, Peart J et al (eds) Respiratory Drug Delivery 2014, Fajardo, Puerto Rico, 2014. DHI Publishing, LLC, River Grove, IL, pp 143-53

Sakagami M, Gumbleton M (2011) Targeted drug delivery through the respiratory system: molecular control on lung absorption and disposition. In: Smyth $H$, Hickey A (eds) Controlled Pulmonary Drug Delivery. Springer, pp 127-142

Salama R, Traini D, Chan H, Young P (2008) Preparation and characterisation of controlled release co-spray dried drug-polymer microparticles for inhalation 2: evaluation of in vitro release profiling methodologies for controlled release respiratory aerosols. Eur J Pharm Biopharm 70(1):145-52

Son Y-J, McConville J (2009) Development of a standardized dissolution test method for inhaled pharmaceutical formulations. Int J Pharm 382(1-2):15-22

Son Y, Horng M, Copley M, McConville J (2010) Optimization of an in vitro dissolution test method for inhalation formulations. Dissolution Technology 17(2):6-13

Stahlhofen W, Gebhart J, Heyder J (1980) Experimental determination of regional deposition of aerosol particles in the human respiratory tract. Am Ind Hyg Assoc J 41:385-98

Suarez S, Gonzalez-Rothi RJ, Schreier H, Hochhaus G (1998) Effect of dose and release rate on pulmonary targeting of liposomal triamcinolone acetonide phosphate. Pharm Res 15:461-5

Talton J, Fitz-Gerald J, Singh R, Hochhaus G (2000) Nano-thin coatings for improved lung targeting of glucocorticoid dry powders: in-vitro and invivo characteristics. In: Dalby R, Byron P, Farr S, Peart J (eds) Respiratory Drug Delivery VII, Tarpon Springs, Florida, 2000. Interpharm Press, pp 67-74

Task Group on Lung Dynamics (1966) Deposition and retention models for internal dosimetry of the human respiratory tract. Health Phys 12:173-207

Tayab Z, Hochhaus G (2005) Pharmacokinetic/pharmacodynamics evaluation of inhalation drugs: application to targeted pulmonary delivery systems. Expert Opin Drug Deliv 2:519-32

USDHHS/FDA (2015) Waiver of In Vivo Bioavailability and Bioequivalence Studies for Immediate-Release Solid Oral Dosage Forms Based on a Biopharmaceutics Classification System, Draft Guidance for Industry. www.fda.gov/downloads/drugs/ guidancecomplianceregulatoryinformation/guidances/ucm070246.pdf. 4 May 2015.

Varma M, Khandavilli S, Ashokraj Y, Dhanikula A, Sood A, Thomas N, Pillai O, Sharma P, Gandhi R, Agrawal S, Nair V, Panchagnula R (2004) Biopharmaceutic classification system: a scientific framework for pharmacokinetic optimization in drug research. Curr Drug Metab 5(5):375-88

Weber B, Hochhaus G (2013) A pharmacokinetic simulation tool for inhaled corticosteroids. AAPSJ 15:159-171 
Weber B, Hochhaus G (2015) A systematic analysis of the sensitivity of plasma pharmacokinetics to detect differences in the pulmonary performance of inhaled fluticasone propionate products using a model-based simulation approach. AAPSJ 17:999-1010

Weers J, Tarara T (2014) The PulmoSphere platform for pulmonary delivery. Ther Deliv 5:277-95

Weibel ER (1963) Morphometry of the human lungs. Springer Verlag, Berlin Widdicombe JH (2002) Regulation of the depth and composition of airway surface liquid. J Anat 201(4):313-8

Submit your manuscript to a SpringerOpen ${ }^{\odot}$ journal and benefit from:

- Convenient online submission

- Rigorous peer review

- Immediate publication on acceptance

- Open access: articles freely available online

- High visibility within the field

- Retaining the copyright to your article

Submit your next manuscript at $\gg$ springeropen.com 